\title{
TLR4 activation of TRPC6-dependent calcium signaling mediates endotoxin- induced lung vascular permeability and inflammation
}

\author{
Mohammad Tauseef, ${ }^{1,2}$ Nebojsa Knezevic, ${ }^{1,2}$ Koteswara R. Chava,, ${ }^{1,2}$ \\ Monica Smith, ${ }^{1,2}$ Sukriti Sukriti, ${ }^{1,2}$ Nicholas Gianaris, ${ }^{4}$ Alexander G. Obukhov, ${ }^{4}$ \\ Stephen M. Vogel, ${ }^{1,2}$ Dean E. Schraufnagel, ${ }^{3}$ Alexander Dietrich, ${ }^{5}$ \\ Lutz Birnbaumer, ${ }^{6}$ Asrar B. Malik, ${ }^{1,2}$ and Dolly Mehta ${ }^{1,2}$ \\ 'Department of Pharmacology, ${ }^{2}$ Center for Lung and Vascular Biology, and ${ }^{3}$ Department of Medicine, University of Illinois \\ College of Medicine, Chicago, IL 61605 \\ ${ }^{4}$ Department of Cellular and Integrative Physiology, Indiana University School of Medicine, Indianapolis, IN 46202 \\ ${ }^{5}$ Walther-Straub-Institute for Pharmacology and Toxicology, Ludwig-Maximilians University, 80336 Munich, Germany \\ ${ }^{6}$ National Institute of Environmental Health Sciences, Research Triangle Park, NC 27709
}

\section{CORRESPONDENCE \\ Dolly Mehta: \\ dmehta@uic.edu}

\section{Abbreviations used: ALI,}

acute lung injury; CLP, cecal ligation and puncture; DAG, diacylglycerol; EBA, Evans blue-conjugated albumin; EC, endothelial cell; HPAEC, human pulmonary arterial EC; IRAK4, IL-1R-associated kinase $4 ; K_{\mathrm{f}, c}$, pulmonary microvessel filtration coefficient; MLEC, mouse lung endothelial cell; MyD88, myeloid differentiation factor 88; MYLK, nonmuscle myosin light chain kinase; OAG, 1-oleoyl-2-acetylsn-glycerol; TLR 4, Toll-like receptor 4; TRPC6, transient receptor potential canonical 6 .

Lung vascular endothelial barrier disruption and the accompanying inflammation are primary pathogenic features of acute lung injury (ALI); however, the basis for the development of both remains unclear. Studies have shown that activation of transient receptor potential canonical (TRPC) channels induces $\mathrm{Ca}^{2+}$ entry, which is essential for increased endothelial permeability. Here, we addressed the role of Toll-like receptor 4 (TLR4) intersection with TRPC6-dependent $\mathrm{Ca}^{2+}$ signaling in endothelial cells (ECs) in mediating lung vascular leakage and inflammation. We find that the endotoxin (lipopolysaccharide; LPS) induces $\mathrm{Ca}^{2+}$ entry in ECs in a TLR4-dependent manner. Moreover, deletion of TRPC6 renders mice resistant to endotoxin-induced barrier dysfunction and inflammation, and protects against sepsis-induced lethality. TRPC6 induces $\mathrm{Ca}^{2+}$ entry in ECs, which is secondary to the generation of diacylglycerol (DAG) induced by LPS. $\mathrm{Ca}^{2+}$ entry mediated by TRPC6, in turn, activates the nonmuscle myosin light chain kinase (MYLK), which not only increases lung vascular permeability but also serves as a scaffold to promote the interaction of myeloid differentiation factor 88 and IL-1R-associated kinase 4, which are required for NF-KB activation and lung inflammation. Our findings suggest that TRPC6-dependent $\mathrm{Ca}^{2+}$ entry into ECs, secondary to TLR4-induced DAG generation, participates in mediating both lung vascular barrier disruption and inflammation induced by endotoxin.

Acute lung injury (ALI) in septic patients is characterized by increased lung vascular permeability and severe lung inflammation, which typically develop in concert and lead to progressive deterioration of lung function (Diaz et al., 2010). LPS, a cell wall component of Gram-negative bacteria, is a causative agent implicated in the pathogenesis of ALI (Andonegui et al., 2003, 2009; Everhart et al., 2006; Mehta and Malik, 2006; Bachmaier et al., 2007; Diaz et al., 2010; Karpurapu et al., 2011). Studies showed that endothelial cells (ECs) are crucial in mediating the lung's inflammatory response by LPS (Andonegui et al., 2003, 2009). LPS binds the endothelial Toll-like receptor 4
(TLR4) via CD14, a membrane-bound glycosylphosphatidyl inositol-anchored protein (Andonegui et al., 2002; Kawagoe et al., 2008; Lloyd-Jones et al., 2008). TLR4 in turn activates signaling pathways responsible for the generation of proinflammatory cytokines via myeloid differentiation factor 88 (MyD88; Kawai et al., 1999; Medvedev et al., 2002; Bachmaier et al., 2007; Kawagoe et al., 2008). MyD88 contains the Toll-IL1-R homology

0 2012 Tauseef et al. This article is distributed under the terms of an AttributionNoncommercial-Share Alike-No Mirror Sites license for the first six months after the publication date (see http://www.rupress.org/terms). After six months it is
the available under a Creative Commons License (Attribution-Noncommercial-Share Alike 3.0 Unported license, as described at http://creativecommons.org/licenses/ by-nc-sa/3.0/). 

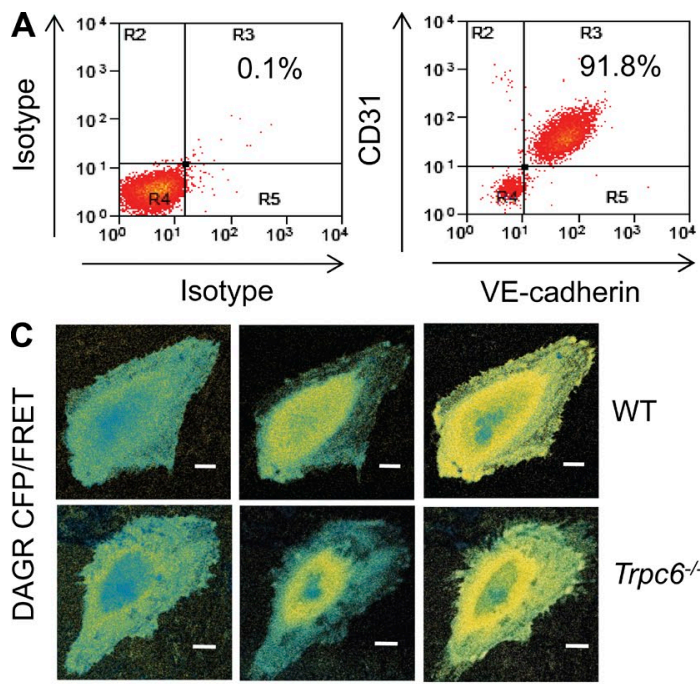

0

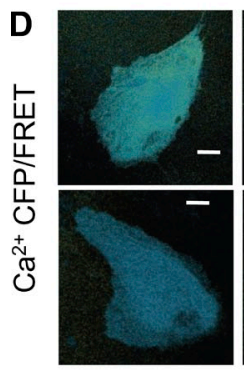

0

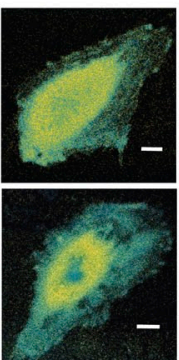

3

min

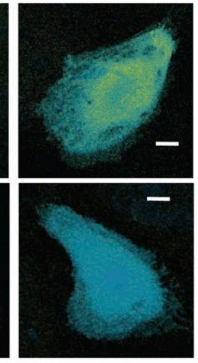

3

min
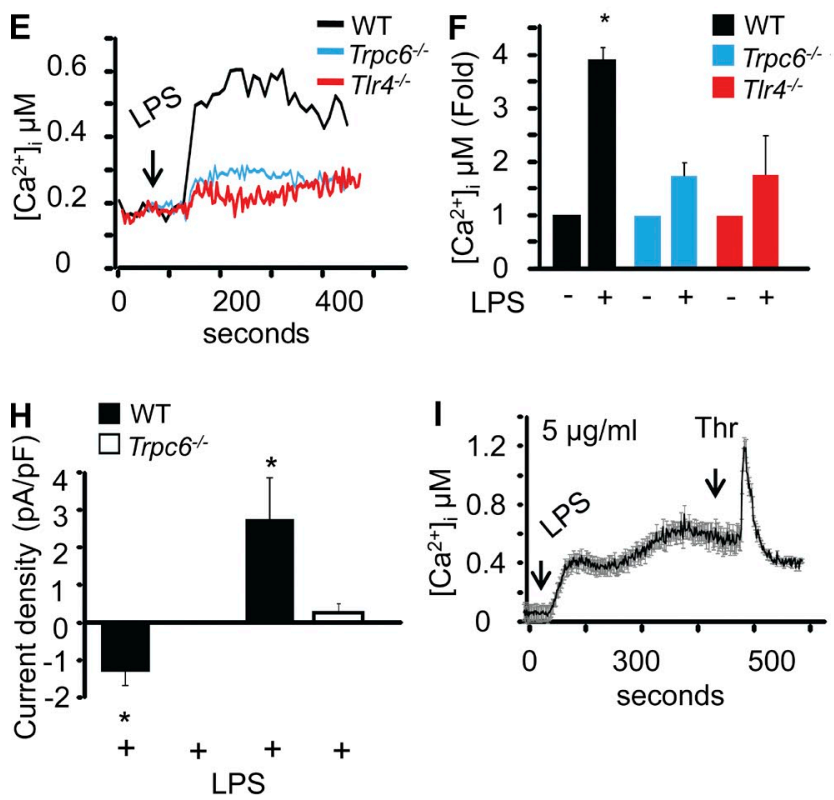
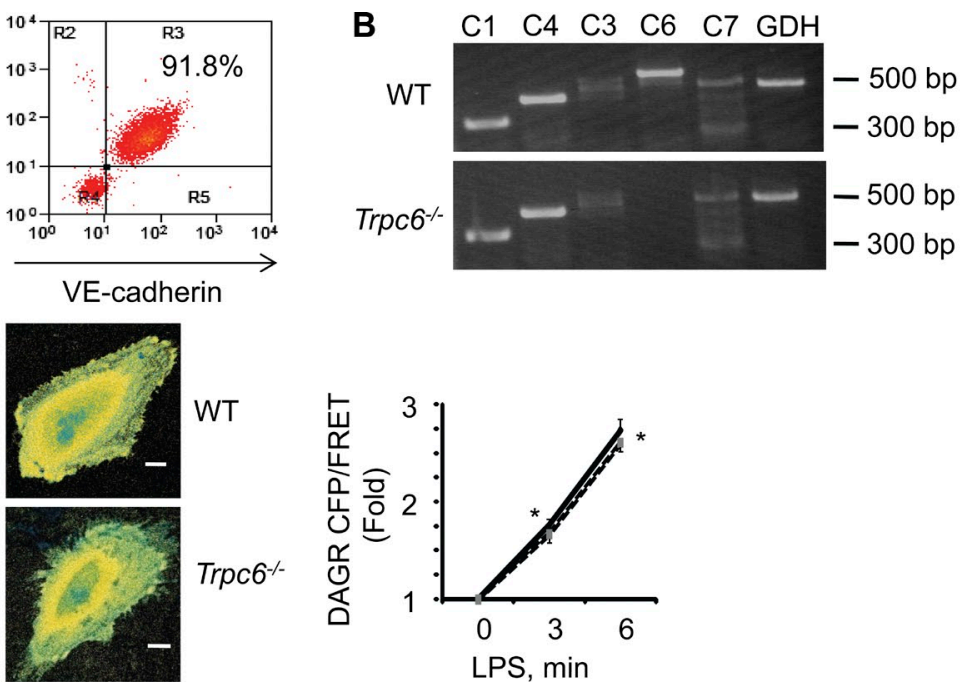

6

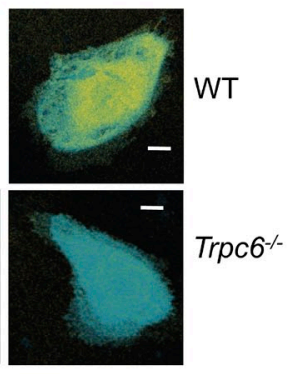

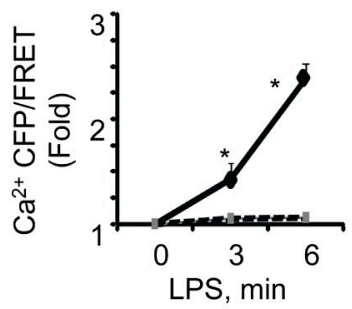

- WT

--- Trpc6-

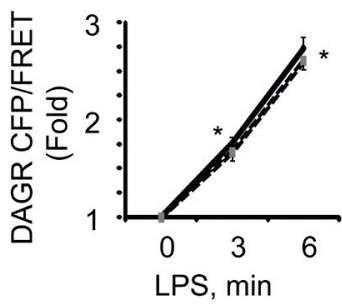

LPS, min
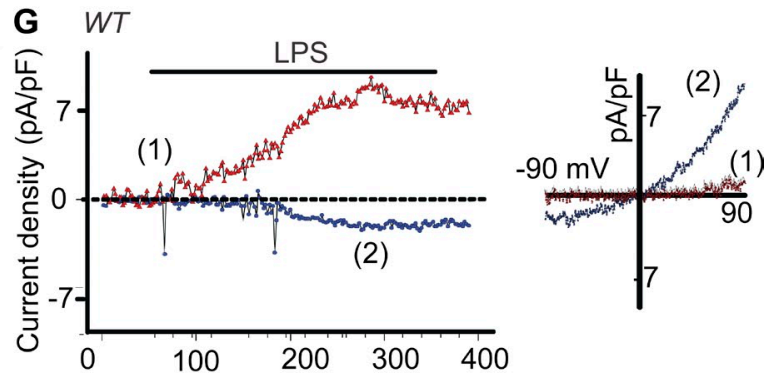
$\operatorname{Trpc6} 6^{-1}$
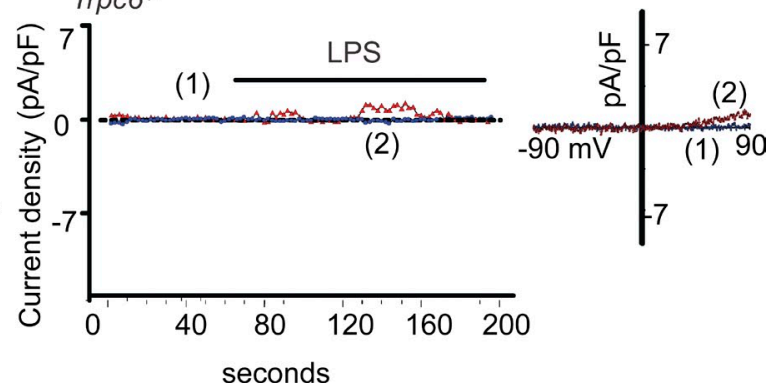

Figure 1. LPS-generated DAG induces $\mathrm{Ca}^{2+}$ entry and activates $\mathrm{Ca}^{2+}$ current in lung ECs in a TRPC6-dependent manner. (A) Dot plot analysis of EC surface markers was performed with WT-MLECs immunostained with APC-tagged VE-cadherin and PE-tagged CD31. WT-MLECS immunostained with APC-IgG and PE-lgG were used as isotype controls. Data are representative of at least two independent experiments. (B) RNA extracted from WT and Trpc6 $6^{-1-}$ MLECs were reverse-transcribed using suitable primers, as described in the Materials and methods. GAPDH was used as internal control. C1, C4, C3, C6, C7, and GDH represent TRPC1, TRPC4, TRPC3, TRPC6, TRPC7, and GAPDH, respectively. (C and D) WT or TRPC6 ${ }^{-1-}$ MLECs were transduced with FRET-based DAG reporter (DAGR; C) or $\mathrm{Ca}^{2+}$ reporter (D). Cells were then stimulated with $1 \mu \mathrm{g} / \mathrm{ml} \mathrm{LPS}$ and dynamic changes in CFP, FRET, and YFP were acquired. DAG and $\mathrm{Ca}^{2+}$ reporter activities were calculated by ratioing CFP/FRET intensity before and 
(TIR) domain and death domain through which MyD88 recruits IL-1R-associated kinase 4 (IRAK4) to the Toll/IL-1 signaling domain, resulting in IRAK4 activation (Medvedev et al., 2002; Kawagoe et al., 2008). IRAK4 activates its effectors IRAK2 and IRAK1 to induce activation of NF-кB and other transcription factors required for the generation of proinflammatory cytokines and reactive oxygen species (ROS) and the activation of MAPK (Medvedev et al., 2002; Kawagoe et al., 2008; Kawai and Akira, 2010; Takeuchi and Akira, 2010). LPS induces lung neutrophil sequestration, as well as neutrophilic and macrophage generation of cytokines and ROS (Andonegui et al., 2002, 2003, 2009; Gao et al., 2002; Garrean et al., 2006; Bachmaier et al., 2007; $\mathrm{Xu}$ et al., 2008; Di et al., 2012), which contribute to the development of ALI (Gao et al., 2002; Bachmaier et al., 2007; Di et al., 2010, 2012). However, ECs may also have a more direct role in mediating LPS-induced loss of lung vascular barrier function and inflammation (Andonegui et al., 2002, 2003, 2009; Wang et al., 2011).

A rise in intracellular $\mathrm{Ca}^{2+}$ is an essential signal required for EC contraction that precedes endothelial barrier disruption (Mehta et al., 2003; Pocock et al., 2004; Cheng et al., 2006; Mehta and Malik, 2006; Singh et al., 2007; Kini et al., 2010; Weissmann et al., 2012). It remains unknown whether $\mathrm{Ca}^{2+}$ signaling intersects with the TLR 4 signaling pathway, and hence contributes to LPS-induced endothelial permeability and inflammation. Diacylglycerol (DAG), a membrane phospholipid-derived second messenger generated by LPS (Sands et al., 1994; Yamamoto et al., 1997; Monick et al., 1999; Zhang et al., 2001; Xu et al., 2005; Zhang et al., 2011), is produced upon hydrolysis of phosphatidylcholine (PC) by PC-specific phospholipase (PLC; Sands et al., 1994; Yamamoto et al., 1997; Zhang et al., 2001; Xu et al., 2005). Yamamoto et al. (1997) demonstrated that LPS induces DAG generation by binding to CD14 (Yamamoto et al., 1997), a component of LPS-binding TLR 4 complex in ECs (Andonegui et al., 2002; Lloyd-Jones et al., 2008). Importantly, DAG is known to activate transient receptor potential canonical 6 (TRPC6) channels, a nonselective $\mathrm{Ca}^{2+}$ permeable ion channel (Hofmann et al., 1999; Dietrich et al., 2005a), which was shown to induce endothelial contraction (Pocock et al., 2004; Singh et al., 2007; Kini et al.,
2010; Weissmann et al., 2012). In this study, we tested the hypothesis that LPS ligation of TLR 4 and resulting TRPC6dependent $\mathrm{Ca}^{2+}$ signaling intersect to mediate both the vascular leak and inflammatory features of ALI.

\section{RESULTS \\ LPS-induced DAG generation stimulates $\mathrm{Ca}^{2+}$ entry and $\mathrm{Ca}^{2+}$ current in ECs via TRPC6}

We first addressed whether LPS generates the second messenger DAG in ECs, which in turn can activate $\mathrm{Ca}^{2+}$ entry via TRPC6. We transduced FRET-based DAG (Violin et al., 2003) and $\mathrm{Ca}^{2+}$ reporters (Kim et al., 2009) in ECs isolated from WT or $\operatorname{Trpc} 6^{-1-}$ mouse lungs, which were stimulated with LPS. Mouse lung ECs (MLECs) were identified usingVE-cadherin and PECAM (CD31) antibodies (Fig. 1 A). LPS exposure of MLECs increased DAG generation and cytosolic $\mathrm{Ca}^{2+}$ in a time-dependent manner, as evident from DAG and $\mathrm{Ca}^{2+}$ reporter activities (Fig. 1 C). TRPC6 deletion did not impair DAG generation by LPS (Fig. $1 \mathrm{C}$ ); rather, it prevented the increase in cytosolic $\mathrm{Ca}^{2+}$ (Fig. 1 D). Loss of TRPC6 also did not alter the expression profile of other TRPC channels (Fig. 1 B).

In other studies, we loaded MLECs with Fura 2-AM to determine cytosolic $\mathrm{Ca}^{2+}$ concentration in response to LPS and its dependence on TRPC6 and TLR4. We found that basal cytosolic $\mathrm{Ca}^{2+}$ concentration did not differ between WT and TRPC6-null ECs (Fig. 1 E). However, LPS caused a fourfold increase in intracellular $\mathrm{Ca}^{2+}$ concentration in WT-MLECs, whereas cytosolic $\mathrm{Ca}^{2+}$ did not increase in TRPC6-null MLECs (Fig. 1, E and F). Moreover, the loss of TLR 4 in MLECs markedly reduced cytosolic $\mathrm{Ca}^{2+}$ response in cells exposed to LPS (Fig. 1, E and F), indicating LPS-induced $\mathrm{Ca}^{2+}$ entry requires TLR 4 expression. We ruled out the contribution of TLR2, another known TLR receptor expressed in ECs (Edfeldt et al., 2002; Bertocchi et al., 2011), in inducing $\mathrm{Ca}^{2}$ transients because the specific TLR2 agonist lipoteic acid (Into et al., 2007) had no effect in increasing intracellular $\mathrm{Ca}^{2+}$ concentration in WT-MLECs (unpublished data).

To validate the $\mathrm{Ca}^{2}$ transient measurements and address whether LPS activates cationic current, we performed wholecell patch-clamp recordings in MLECs. Within 1 min of addition

after stimulation with LPS (left). Plot shows mean \pm SEM from three individual experiments (right). ${ }^{*}$ indicates a significant increase in reporter activity over time zero $(\mathrm{P}<0.05)$. Bars, $5 \mu \mathrm{m}$. (E and F) WT, Trpc6 ${ }^{-1-}$, or T/r4 $4^{-1-}$ MLECs loaded with Fura 2-AM for 25 min were stimulated with $1 \mu \mathrm{g} / \mathrm{ml}$ LPS and Fura 2 at a ratio of 340:380 was recorded. Intracellular $\mathrm{Ca}^{2+}$ concentrations were then calculated as described in Materials and methods. Representative traces show a mean $\mathrm{Ca}^{2+}$ response of 20-25 WT, Trpc6 $6^{-1-}$, or T/r $4^{-/-}$ECs in a given field (E). Plot shows mean \pm SEM of changes in intracellular $\mathrm{Ca}^{2+}$ concentration after (+) stimulation of MLECs with LPS from 2-3 independent experiments (F). ${ }^{*}$ indicates an increase in intracellular $\mathrm{Ca}^{2+}$ after addition of LPS (P<0.05). (G, left) Representative traces of LPS-elicited, leak-subtracted currents obtained during voltage ramps from $-90 \mathrm{mV}$ to $+90 \mathrm{mV}$ in a WT MLEC (top) and a Trpc6 ${ }^{-1-}$ MLEC (bottom). Circles indicate current densities at $-90 \mathrm{mV}$, whereas the triangles show current densities at $+90 \mathrm{mV}$. The holding potential was $-60 \mathrm{mV}$. Horizontal bars indicate times when LPS was added to the bath. (right) Current-voltage relationships obtained during ramps from $-90 \mathrm{mV}$ to $90 \mathrm{mV}$ at times indicated with (1) and (2) in a WT and TRPC6 ${ }^{-1-}$ MLECs. (H) Plot shows mean peak current densities of LPS-elicited currents obtained at a holding potential of $-90 \mathrm{mV}$ from 7 wild type and 5 Trpc $6^{-1-}$ MLECs. ${ }^{*}$ indicates significant increase in current after addition of LPS $(\mathrm{P}<0.05)$. (I) WT-MLECs loaded with Fura 2-AM for 25 min were stimulated with $5 \mu \mathrm{g} / \mathrm{ml}$ LPS, and Fura 2 ratio at 340:380 was recorded. Intracellular $\mathrm{Ca}^{2+}$ concentration were then calculated as described in Materials and methods. Representative trace shows mean $\mathrm{Ca}^{2+}$ response of 20-25 MLECs to $50 \mathrm{nM}$ thrombin after LPS stimulation ( $\left.5 \mu \mathrm{g} / \mathrm{ml}\right)$. Experiments were repeated at least three times. 
of LPS in the bath, we observed a cationic current in WT cells with the peak response occurring within 5 min (Fig. $1 \mathrm{G}$, top left). The outward current at $+90 \mathrm{mV}$ was considerably greater in amplitude than inward current at $-90 \mathrm{mV}$. The currentvoltage (I-V) relationship for LPS-induced current showed outward rectification that reversed at potential of $0 \mathrm{mV}$ (Fig. $1 \mathrm{G}$, top right), indicating these currents were mediated by nonselective cation channels. Importantly, the LPS-induced current was inhibited by $>90 \%$ in TRPC6 ${ }^{-/-}$MLECs (Fig. 1, G [bottom] and $\mathrm{H}$ ), indicating the dominant role of TRPC6 channels in the response. We observed that $5 \mu \mathrm{g} / \mathrm{ml}$ LPS did not alter cell viability in that ECs remained fully responsive to thrombin after stimulation (Fig. 1 I).

In other studies, we used 1-oleoyl-2-acetyl-sn-glycerol (OAG), a cell-permeable DAG analogue, to address whether DAG activation of TRPC6 could increase lung vascular permeability. Using isolated/perfused mouse lungs (described in Materials and methods), we determined pulmonary microvessel filtration coefficient $\left(K_{\mathrm{f}, \mathrm{c}}\right)$, a measure of vascular endothelial permeability to liquid (Vogel et al., 2000; Tauseef et al., 2008). OAG produced a fourfold increase in $K_{\mathrm{f}, \mathrm{c}}$ in WT mouse lungs, but failed to elicit a response in $\operatorname{Trpc} 6^{-1-}$ lungs (Fig. 2 B). Importantly, basal $K_{\mathrm{f}, \mathrm{c}}$ values did not differ in WT and Trpc6 $6^{-/-}$ lungs (Fig. 2 A). To determine whether OAG could also increase lung vascular permeability in vivo (as opposed to the aforementioned isolated/perfused organ), we injected OAG or control vehicle i.v. in mice and measured pulmonary transvascular leakage of Evans blue-labeled albumin (Tauseef et al., 2008; Knezevic et al., 2009). Infusion of OAG increased transendothelial albumin influx in WT lungs whereas the response was inhibited in Trpc6 $6^{-/-}$lungs (Fig. 2 C). OAG increased intracellular $\mathrm{Ca}^{2+}$ in WT-MLECs but not in Trpc6 ${ }^{-1-}$ MLECs (Fig. 2 A). OAG did not increase intracellular $\mathrm{Ca}^{2+}$ in WTMLECs in the absence of extracellular $\mathrm{Ca}^{2+}$ (Fig. 2 A). Together these studies show that OAG activates the TRPC6 $\mathrm{Ca}^{2+}$ entry pathway to induce lung vascular permeability.

\section{Involvement of TRPC6 in mediating LPS-induced lung vascular barrier disruption and inflammation}

We next addressed the possibility that TRPC6 was important in mediating lung injury after direct LPS exposure via airway instillation (Tauseef et al., 2008; Knezevic et al., 2009). Transendothelial albumin leakage in lungs was increased 4-8-fold from baseline at the 2- and 4-h time points, respectively (Fig. $3 \mathrm{~A}$ ). The increase in lung vascular permeability and edema formation were not seen in $\operatorname{Trpc} 6^{-/-}$mice (Fig. 3, B and C). Also LPS-induced increase in myeloperoxidase (MPO) activity and leukocyte sequestration were markedly reduced in lungs of $\operatorname{Tr} c 6^{-1-}$ mice compared with WT mice (Fig. 3, D and E). These results demonstrate that TRPC6 is crucial in mediating both lung vascular leakage and inflammation induced by LPS.

TRPC6-mediated increase in lung endothelial permeability is not dependent on recruitment of myeloid cells

To determine the contributions of myeloid cells and ECs in mediating LPS-induced increase in lung vascular permeability, we transplanted WT BM cells into lethally irradiated Trpc $\sigma^{-/-}$ mice (WT $\rightarrow \operatorname{Trpc}^{-1-}$ chimera) or WT mice (WT $\rightarrow$ WT chimera) and vice versa $\left(\operatorname{Trpc} \sigma^{-1-} \rightarrow \mathrm{WT}\right.$ chimera; $\operatorname{Trp} c \sigma^{-1-} \rightarrow$
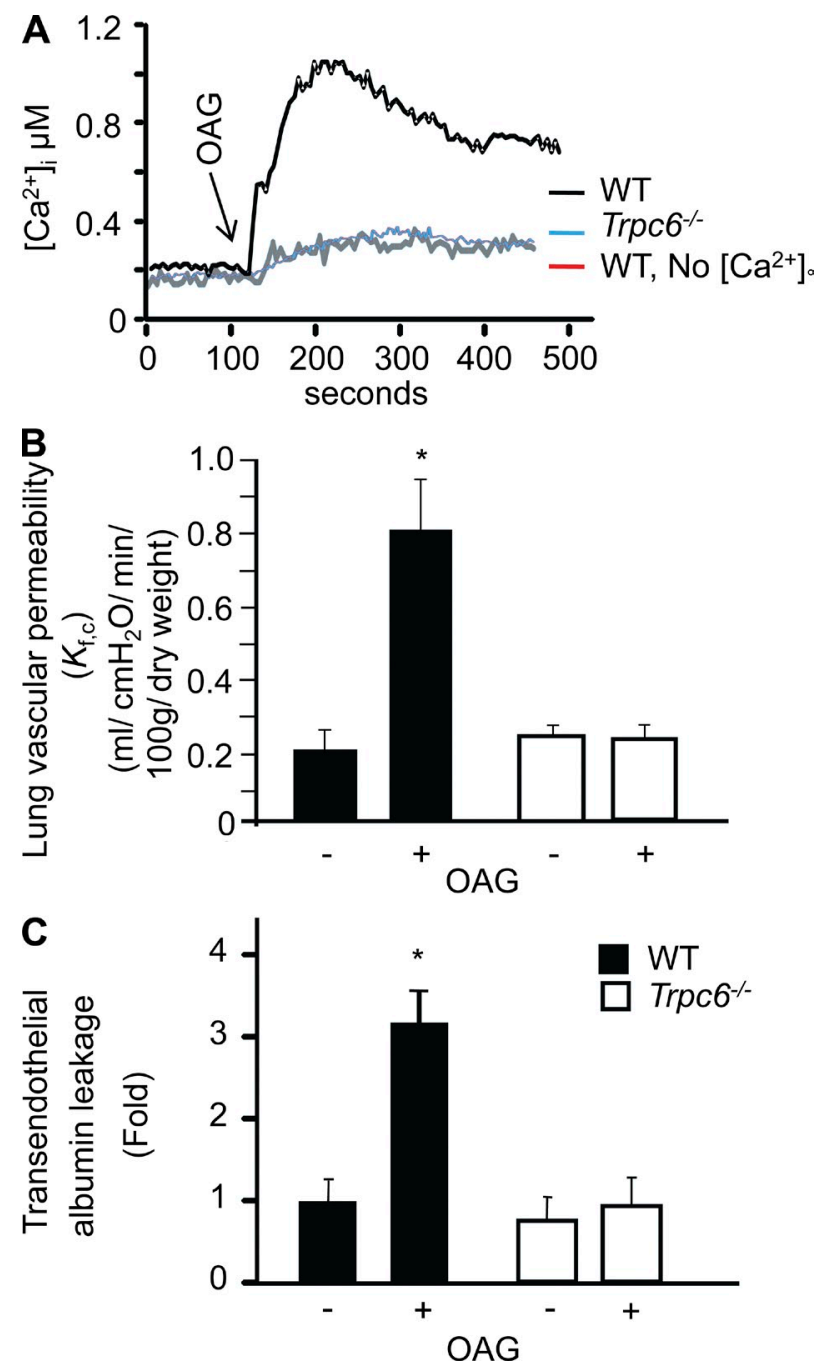

Figure 2. Direct activation of TRPC6 increases lung vascular permeability. (A) WT or Trpc6 ${ }^{-1-}$ MLECs were loaded with Fura 2-AM for $25 \mathrm{~min}$, after which they were exposed to buffer containing $2 \mathrm{mM}$ $\mathrm{Ca}^{2+}$ or $\mathrm{Ca}^{2+}$-free buffer. Changes in intracellular $\mathrm{Ca}^{2+}$ were determined in response to OAG by converting 340:380 excitation ratio intensity, as described in Materials and methods. Each representative tracing is the mean calcium response of 20-25 cells in a given field. These experiments were repeated three times. (B) Isogravimetric WT or Trpc6 $6^{-1}$ mice lungs were perfused with $100 \mu \mathrm{M} O \mathrm{OAG}$ for $20 \mathrm{~min}$, after which intravascular pressure was raised by $10 \mathrm{~cm}$ of $\mathrm{H}_{2} \mathrm{O}$. Microvascular filtration coefficient $\left(K_{\mathrm{f}, \mathrm{c}}\right)$ was determined from the slope of lung wet weight gain after normalization by lung dry weight, as described in Materials and methods. Plot shows mean \pm SEM of $K_{\mathrm{f}, \mathrm{C}}$ from four individual experiments. ${ }^{*}$ indicates a significant increase in $K_{f, c}$ over the values without OAG $(0 \mu \mathrm{M} ; \mathrm{P}<0.05)$. (C) OAG (100 $\mu \mathrm{M})$ was administered retroorbitally into the WT or $\operatorname{Trpc}^{-/-}$mice vasculature for $20 \mathrm{~min}$, after which Evans blue-labeled albumin was injected and transendothelial leakage was determined at 30 min. Plot shows mean \pm SEM of albumin leakage from four individual experiments. ${ }^{*}$ indicates values that are significantly different from $\operatorname{Trpc}^{-1-}$ lungs without OAG or after $\mathrm{OAG}$ administration in $\operatorname{Trpc} 6^{-1-}$ mice $(\mathrm{P}<0.05)$. 
Trpc $6^{-1-}$ chimera). All mice were studied after confirming engraftment of donor (either WT or Trpc6 $6^{-1-}$ ) BM cells in the recipient mice (Fig. $4 \mathrm{~A}$ ). Challenging WT $\rightarrow$ WT chimera mice with LPS resulted in increased lung vascular permeability and induced edema (Fig. 4, B and C). However, challenging $\mathrm{WT} \rightarrow \operatorname{Trpc}^{-1-}$ chimera mice with LPS failed to induce increase in lung vascular permeability and prevented edema (Fig. 4, B and C). In addition, LPS increased lung vascular permeability and edema formation in $\operatorname{Trpc} 6^{-/-}$ $\rightarrow$ WT chimeric mouse to a similar extent as in WT $\rightarrow$ WT chimera mice, whereas $\operatorname{Trpc}^{-/-} \rightarrow \mathrm{TRPC6}^{-/-}$chimera mice failed to respond to LPS (Fig. 4, B and C). Thus, TRPC6 expression in myeloid cells was not responsible for LPS-induced increase in lung vascular permeability and edema formation, indicating the primary importance of TRPC6 in ECs in mediating leaky lung vessels.

\section{Deletion of TRPC6 renders mice resistant to sepsis}

We next investigated the role of TRPC6 in sepsis-induced mortality in response to LPS. LPS challenge (40 $\mathrm{mg} / \mathrm{kg}$ i.p.) resulted in $90 \%$ mortality in WT mice, whereas $80 \%$ of $\operatorname{Trpc} 6^{-/-}$ mice survived (Fig. 5 A). Because LPS binding to TLR 4 triggers an immune response (Andonegui et al., 2003, 2009), we surmised that TRPC6 deletion would also impair cytokine generation. After LPS exposure, the levels of IL-6, IFN- $\gamma$, TNF, and $\mathrm{KC}$ were significantly lower in TRPC6-null lungs than in WT lungs (Fig. 5 B). In other studies, we induced polymicrobial sepsis by cecal ligation and puncture (CLP) in mice to address whether loss of TRPC6 could prevent death in this more severe sepsis model. All WT mice died within $50 \mathrm{~h}$ after CLP (Fig. 5 C), whereas only $40 \%$ of $\operatorname{Trpc} 6^{-/-}$mice died within 50 h, and some of these mice survived up to $150 \mathrm{~h}$ (Fig. $5 \mathrm{C}$ ). Also, we assessed cytokine generation after $22 \mathrm{~h}$ CLP because at this time point we noted first lethality in WT mice. CLP-induced increase in levels of IL-6, IFN- $\gamma$, TNF, and KC were significantly lower in TRPC6-null lungs than WT lungs (Fig. 5 D).

\section{TRPC6 is required for NF-KB signaling induced by LPS}

As the aforementioned prevention of increased lung vascular permeability and inflammation in TRPC6-null mice may be caused by reduced TLR4-mediated NF- $\kappa \mathrm{B}$ activation, we determined phosphorylation of the NF- $\mathrm{KB}$ p65 subunit and NF- $\mathrm{kB}-$ dependent ICAM-1 expression inTRPC6-null

Figure 3. Deletion of TRPC6 prevents lung vascular permeability, edema, and inflammation induced by LPS. (A) WT mice were exposed to nebulized LPS $(1 \mathrm{mg} / \mathrm{ml})$ for $1 \mathrm{~h}$. After $3.5 \mathrm{~h}$ of LPS exposure, Evans blue-labeled albumin was injected retroorbitally into each mouse to assess lung vascular hyperpermeability. Data represent mean \pm SEM of four individual experiments. ${ }^{*}$ indicates significant increase from the PBS-exposed group $(P<0.05)$. (B and C) WT and Trpc6 ${ }^{-/-}$mice were exposed to nebulized LPS for $1 \mathrm{~h}$. After $3.5 \mathrm{~h}$ of LPS exposure, Evans blue-labeled albumin was injected retroorbitally into mice. Evans blue albumin extravasation from lungs or plasma (C) and lung wet/dry ratio (D) were determined after $30 \mathrm{~min}$. Data represent mean \pm SEM from four individual experiments. ${ }^{*}$ indicates significant increase from PBS-exposed group $(P<0.05)$. (D) Lungs from nebulized, LPS-exposed WT and Trpc6 $^{-1-}$ mice were homogenized, and myeloperoxidase (MPO) activity was determined. Data are shown as mean \pm SEM of three individual experiments. * indicates significant increase in MPO activity compared with WT lungs after PBS challenge or $\mathrm{TRPC6}^{-/-}$ lungs receiving PBS or LPS $(P<0.05)$. (E) $4 \mathrm{~h}$ after nebulized LPS exposure, WT and Trpc6-/- lungs were fixed, sectioned, and stained with hematoxylin. The images shown at the left panel are representative sections (Bars, $10 \mu \mathrm{m}$ ), and quantitative results for leukocyte infiltration are shown in right panel. Data represent mean \pm SEM of three individual experiments * indicates significant increase in neutrophils counts compared with WT lungs after PBS challenge or TRPC6 ${ }^{-1-}$ lungs receiving PBS or LPS $(\mathrm{P}<0.05)$. 


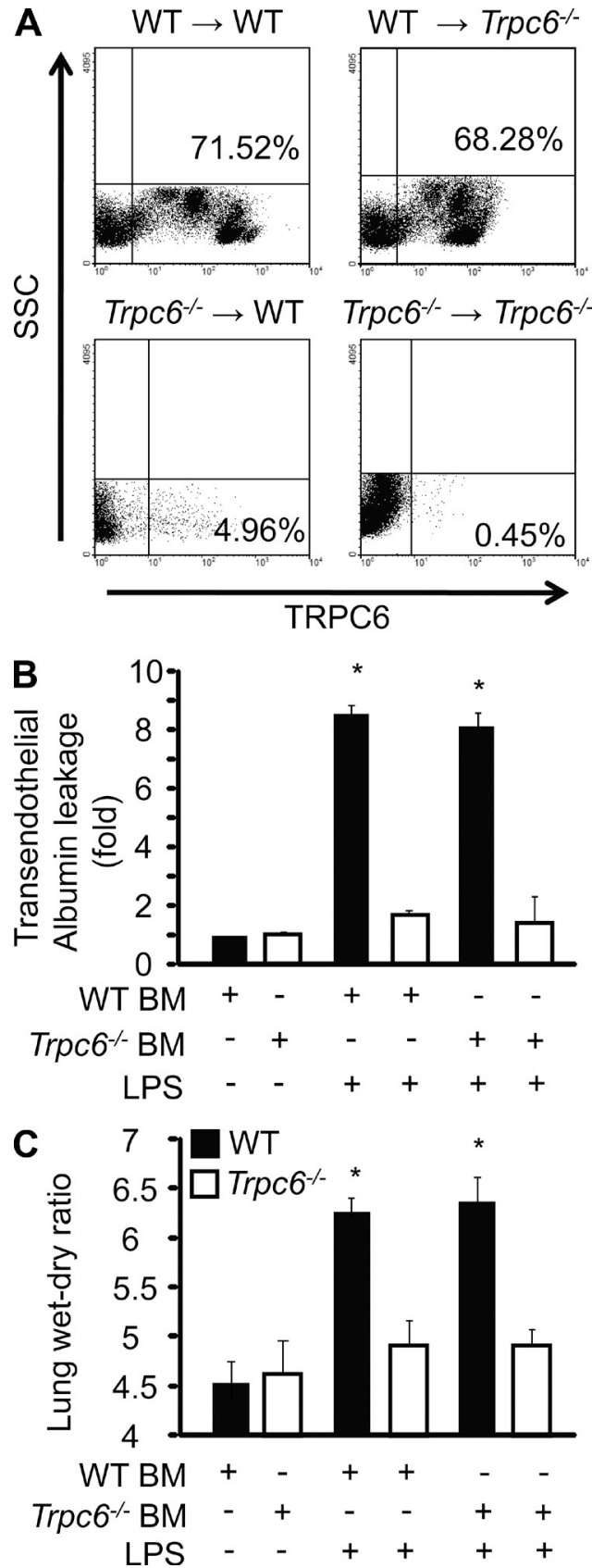

Figure 4. Effect of BM cells transplantation on LPS-induced increase in lung vascular permeability and edema formation. After irradiation, WT mice were injected with WT or TRPC6 ${ }^{-1}$ BM cells. In parallel, TRPC6 $^{-1}$ mice were injected with WT BM cells or TRPC6 ${ }^{-1-}$ BM cells. At 6 wk after BM transplantation, BM cells were isolated from WT or TRPC6 ${ }^{-/}$chimeric mice, fixed, and incubated with anti-TRPC6 antibody followed by Alexa Fluor 488 secondary antibody. Data were analyzed using WinMdi software. Dot plots from two such experiments were generated after gating all BM cells from respective groups of mice against side scatter population, as described in Materials and methods (A). Chimeric mice were exposed to nebulized LPS (1 mg/ml) for $1 \mathrm{~h}$. After $3.5 \mathrm{~h}$, Evans blue-labeled albumin was injected retroorbitally into each mouse as described in Materials and methods. Mice were sacrificed at $4 \mathrm{~h}$ to determine lung vascular albumin permeability (B), and lung wet/dry ratio (C). Data represent mean \pm SEM from three independent experiments. ${ }^{*}$ indicates values greater than values in WT or Trpc $6^{-1-}$ lungs without LPS $(P<0.05)$. mice. LPS induced p65 phosphorylation and ICAM-1 expression beginning at $2 \mathrm{~h}$, increased markedly at $4 \mathrm{~h}$, and remained elevated above baseline up to $8 \mathrm{~h}$ (Fig. $6 \mathrm{~A}$ ). These changes did not occur in TRPC6-null mouse lungs (Fig. 6 B). LPS also failed to induce ICAM-1 expression in ECs isolated from TRPC6null mouse lungs (Figs. 6 C). LPS markedly increased production of TNF, IFN- $\gamma, \mathrm{KC}$, and IL-6 in WT lungs whereas this was greatly reduced in Trpc6 $6^{-/-}$mouse lungs (Fig. 6 D).

\section{Requirement of MYLK activation downstream of TRPC6 in mediating LPS-induced lung endothelial permeability and NF-KB activation}

Because the nonmuscle isoform of myosin light chain kinase (MYLK), a $\mathrm{Ca}^{2+}$-calmodulin-dependent enzyme present in ECs, plays a key role in inducing lung endothelial permeability and inflammation (Garcia et al., 1995; Garcia et al., 1997; Wainwright et al., 2003; Wadgaonkar et al., 2005b; Mehta and Malik, 2006; Ralay Ranaivo et al., 2007; Rossi et al., 2007), we addressed the possibility that MYLK activation downstream of TRPC6 signaling may be a crucial factor in promoting both lung endothelial barrier dysfunction and inflammation. Thus, isolated-perfused lungs from $M y l k^{-1-}$ mice (Wainwright et al., 2003) were challenged with OAG to activate TRPC6, and $K_{\mathrm{f}, \mathrm{c}}$ was measured. Deletion of MYLK markedly reduced the OAG-mediated increase in lung vascular permeability (Fig. 7 A). Similar to TRPC6-null mouse lungs, MYLK-null mouse lungs failed to elicit NF- $\mathrm{KB}$ signaling, lung vascular permeability, and edemagenesis in response to LPS (Fig. 7, B-D). To corroborate the above findings that TRPC6 induces MYLK enzymatic activity, we observed that LPS induced MLC phosphorylation in WT mouse lungs, whereas the response was blocked in MYLK-null mouse lungs similar to findings in TRPC6-null mice (Fig. 7 E).

We next addressed the causal role of TRPC6-dependent $\mathrm{Ca}^{2+}$ entry in mediating NF- $\mathrm{KB}$ signaling. These studies were made by transducing human pulmonary endothelial (HPAE) cells with dominant-negative (DN) TRPC6 mutant ( $\Delta 678-680$ TRPC6 mutant).As predicted, DN-TRPC6 mutant-expressing cells showed markedly suppressed $\mathrm{Ca}^{2+}$ entry in response to OAG (Fig. 7 F). Importantly, LPS failed to induce p65 phosphorylation and ICAM-1 expression in cells transducing DNTRPC6 mutant (Figs. 7 F). NF- $\mathrm{BB}$ signaling in response to LPS was also prevented in ECs transduced with the kinase-defective (KD) MYLK mutant (Blue et al., 2002; Giannone et al., 2004; Fig. 7 F). Moreover, LPS failed to induce MLC phosphorylation in cells expressing either DN-TRPC6 or KD-MYLK mutants. Thus, TRPC6 stimulation and resultant $\mathrm{Ca}^{2+}$ entry activated MYLK that in turn signaled both lung vascular permeability and inflammation in response to LPS.

\section{TRPC6 induces MYLK-dependent MyD88 interaction with IRAK4 to activate NF-кB}

By forming the inflammasome, consisting of TIRAP and interleukin-1 receptor-associated kinases (IRAK4), MyD88 mediates activation of the NF- $\mathrm{B}$ pathway downstream of TLR4 (Medvedev et al., 2002; Kawagoe et al., 2008). As the 
above findings showed that TRPC6 and MYLK lie upstream of NF- $\mathrm{KB}$ activation and that TRPC6 requires MYLK to induce lung vascular permeability, we addressed whether TRPC6 functioned through MYLK to induce formation of the MyD88 and IRAK4 complex required for NF- $\mathrm{KB}$ activation. Lung lysates from LPS-challenged WT mice were immunoprecipitated with anti-MYLK antibody, followed by immunoblotting with anti-MyD88 or anti-IRAK4 antibody to assess their interactions. We found that MYLK interacted with MyD88 basally but, crucially, the interaction of MYLK with IRAK 4 increased up to $4 \mathrm{~h}$ after LPS and declined within 8 h (Fig. 8 A). Next, we determined whether TRPC6induced MYLK signaling was required for the interaction between MyD88 and IRAK4 downstream of TLR4. LPS failed to induce the interaction between MyD88 and IRAK4 in both $\operatorname{Trpc}^{-/-}$and $M y l k^{-1-}$ mouse lungs (Fig. 8 B). Further, MyD88 failed to interact with MYLK and IRAK4 in ECs in which TRPC6 and MYLK function was impaired by either expressing DN-TRPC6 mutant or KD-MYLK mutant (Fig. 8, C and D). Thus, TRPC6-induced $\mathrm{Ca}^{2+}$ entry and the resultant $\mathrm{Ca}^{2+}$ signaling-dependent MYLK activation were responsible for activating TLR 4 signaling secondary to the MYLK-induced MyD88-IRAK4 interaction.

\section{Rescuing TRPC6 expression in $\operatorname{Trpc6}^{-/-}$mice restores leakiness of lung vessels induced by LPS}

To address whether TRPC6 expression was required and sufficient for the LPS-induced increase in lung vascular permeability and inflammation, we transduced WT-TRPC6 cDNA in TRPC6-null lung vascular endothelium using liposomes (Holinstat et al., 2006; Knezevic et al., 2009).WT mice injected with liposomes containing vector were used as controls. Immunostaining of TRPC6-null lung sections expressing TRPC6 cDNA showed TRPC6 localization in pulmonary vascular ECs as identified by anti-VE-cadherin co-immunostaining (Fig. 9 A). Restoration of TRPC6 expression in Trpc6 $6^{-/-}$lung
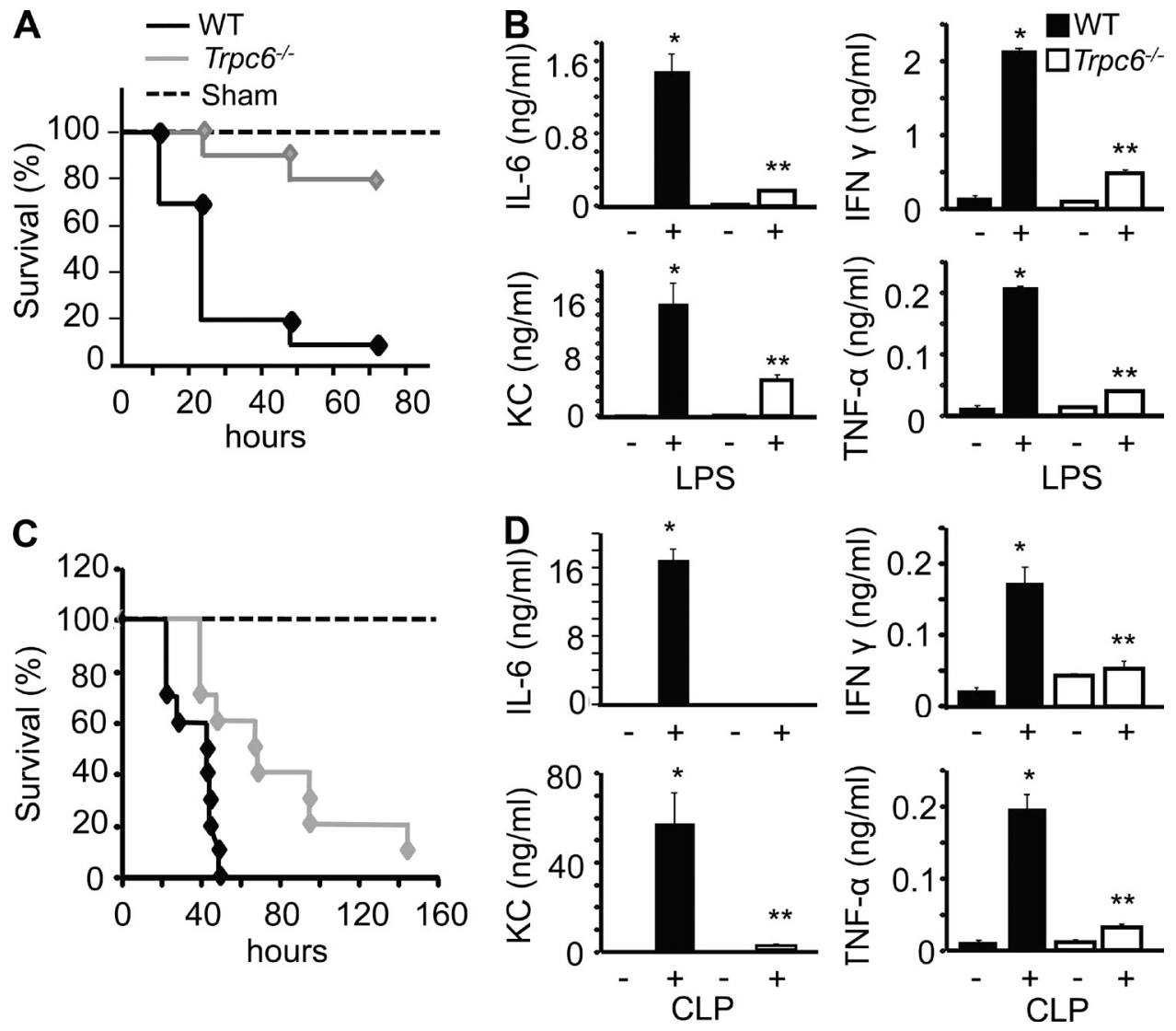

Figure 5. Role of TRPC6 in mediating LPS-induced mortality and proinflammatory cytokine production in mice. (A) Mice were challenged i.p. (40 mg/kg body weight) with LPS and their survival was assessed by log-rank test using 15 mice in each group. (B) Mice were sacrificed $\sim 25 \mathrm{~h}$ after i.p. injection of LPS (40 mg/kg body weight), and the levels of proinflammatory cytokines were determined in lung lysates using mouse Bio-Plex Multiplex Cytokine Assay kit (Bio-Rad Laboratories). Data represent mean \pm SEM from three independent experiments. * indicates values significantly higher than values in WT or TRPC6 ${ }^{-/-}$lungs without LPS $(P<0.05) .{ }^{* *}$ indicates values significantly lower than values in WT lungs after LPS $(P<0.05)$. (C) CLP was induced in WT and TRPC6 ${ }^{-1-}$ mice as described in Materials and methods, and their survival was assessed using log-rank test. A total of 15 mice were used in each group. (D) CLP-induced cytokine generation in lungs was determined after $22 \mathrm{~h}$ of CLP. Data represent mean \pm SEM from three independent experiments. ${ }^{*}$ indicates values significantly higher than values in WT lungs without CLP. ${ }^{* *}$ indicates values significantly lower than values in WT Iungs after CLP $(P<0.05)$. 
ECs rescued both OAG- and LPS-induced $\mathrm{Ca}^{2+}$ entry (Fig. 9, $\mathrm{B}$ and C). Expression of TRPC6 in TRPC6-null lungs significantly increased lung trans-endothelial albumin leakage and edema formation in response to LPS to the same level seen in WT lungs (Fig. 9, D-E).

\section{DISCUSSION}

We have identified in these studies a novel function of TRPC6 in ECs in mediating LPS/TLR4-induced lung vascular permeability and $\mathrm{NF}-\kappa \mathrm{B}-$ dependent lung inflammation. We showed that LPS induces the production of the second messenger DAG in ECs, which directly activates the cation channel TRPC6 and does so in a TLR4-dependent manner. TRPC6-mediated $\mathrm{Ca}^{2+}$ entry in turn activated MYLK, a regulator of endothelial contractility (Garcia et al., 1995, 1997; Mehta and Malik, 2006; Ralay Ranaivo et al., 2007; Rossi et al., 2007). Importantly, MYLK also functioned as a scaffold to promote MyD88 and IRAK4 interaction, resulting in LPS/ TLR4-mediated NF- $\mathrm{KB}$ activation and contributing to the mechanism of lung inflammation. Thus, our results demonstrate that TRPC6- $\mathrm{Ca}^{2+}$ signaling-dependent activation of MYLK in ECs was required for increasing both lung vascular permeability and interaction of MyD88 and IRAK4 components of LPS/TLR4-signaling machinery required for inflammation, the two key features of ALI.

Previous studies have shown a key role of the ECexpressed TLR 4 in mediating the early stages of the increased vascular permeability and inflammatory responses by LPS (Andonegui et al., 2009; Rossi et al., 2007; Zhou et al., 2009). LPS besides serving as a TLR 4 ligand also activates phosphatidylcholine (PC)-specific PLC (Zhang et al., 2001), which metabolizes PC into DAG (Sands et al., 1994; Xu et al., 2005; Yamamoto et al., 1997; Zhang et al., 2001). As DAG is known to activate the TRPC isoform TRPC6 (Dietrich et al., 2005a; Hofmann et al., 1999; Kini et al., 2010; Mehta and Malik, 2006; Sel et al., 2008; Singh et al., 2007), we surmised that LPS/TLR4 signaling intersects with TRPC6-mediated $\mathrm{Ca}^{2+}$ signaling in ECs to increase lung vascular permeability and
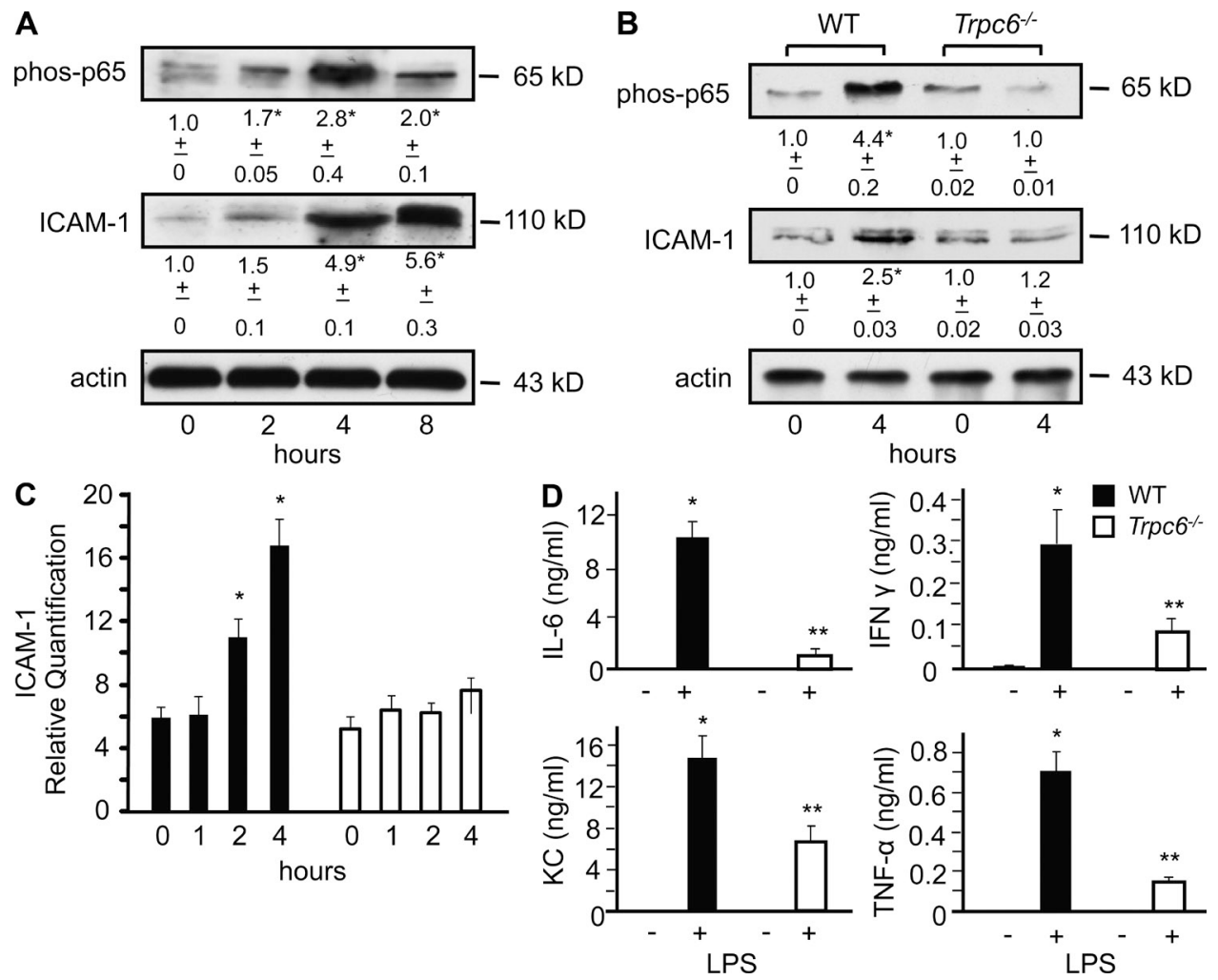

Figure 6. TRPC6 is required for LPS-induced NF-кB activation and inflammatory cytokine production. (A) WT mice were exposed to nebulized PBS or LPS for $1 \mathrm{~h}$. Lungs were isolated at the indicated times. Lung lysates were immunoblotted with either phosphoSer536-p65 antibody or ICAM-1 antibody. Densitometric analysis represents mean \pm SD of three individual experiments. * indicates significant increase from PBS-exposed group (P< 0.05$)$. (B) WT and Trpc6 $6^{-1-}$ lungs were exposed to PBS or $1 \mathrm{mg} / \mathrm{ml}$ LPS challenge. Lungs were harvested at the indicated times, and lysates were immunoblotted with either phosphoSer536-p65 antibody or ICAM-1 antibody. Blots were probed with anti-actin antibodies to verify equal protein loading. Densitometric analysis represents mean \pm SD of three individual experiments. ${ }^{*}$ indicate values significantly different from values at $0 \mathrm{~h}(\mathrm{P}<0.05)$. (C) WT and Trpc6 ${ }^{-/-}$ MLECs were exposed to LPS for indicated times. mRNA was isolated and analyzed for ICAM 1 expression by real-time PCR. Data represent mean \pm SD of three individual experiments. * indicates values higher than values in WT-MLECs at 0 or $2 \mathrm{~h}$, or values in TRPC6 ${ }^{-/-}$MLECS after LPS challenge. (D) WT and $\operatorname{Trpc} 6^{-/}$lungs harvested $4 \mathrm{~h}$ after nebulized LPS challenge were homogenized using RIPA buffer. A total of $100 \mu \mathrm{l}$ of each lung lysate was used for the determination of cytokines using mouse Bio-Plex Multiplex Cytokine Assay kit. Data are expressed as mean \pm SD of three independent experiments. * indicates significance from control group $(\mathrm{P}<0.05)$. 
also induce inflammation. Our results showed that LPS mediates robust DAG generation in ECs as also shown for other cells (Monick et al., 1999; Sands et al., 1994; Yamamoto et al., 1997; Zhang et al., 2001; Zhang et al., 2011). We showed for the first time that LPS activated $\mathrm{Ca}^{2+}$ current directly in ECs. Using TRPC6-null mice, we observed that the LPSinduced DAG generation failed to increase $\mathrm{Ca}^{2+}$ current and lung vascular permeability, thus identifying TRPC6 as the predominant TRPC channel in ECs mediating $\mathrm{Ca}^{2+}$ entry and the LPS-induced loss of lung vascular barrier function. However, ECs lacking TLR 4 showed markedly suppressed $\mathrm{Ca}^{2+}$ entry in response to LPS, indicating that LPS-induced TRPC6 activity requires TLR 4 expression. Although we could not show the correlation between appearance of DAG signal and TRPC6-mediated $\mathrm{Ca}^{2+}$ signal, our results clearly showed that TRPC6-null cells generated DAG but showed no increase in $\mathrm{Ca}^{2+}$ current or cytosolic $\mathrm{Ca}^{2+}$ rise in response to LPS; thus, it is apparent that DAG generation occurred upstream of TRPC6 activation. We also did not observe a compensatory TRPC3 expression (another DAG-sensitive $\mathrm{Ca}^{2+}$ entry channel) in the TRPC6-null ECs as reported for cerebral artery smooth muscle cells (Dietrich et al., 2005b). Additionally, expression of other TRPC channels in TRPC6null ECs was not affected in TRPC6-null ECs, ruling out the
A
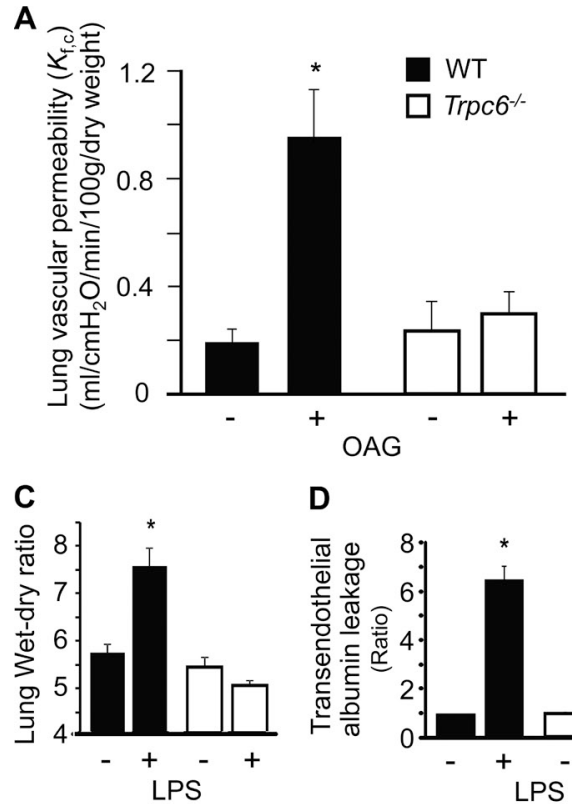

D

$\mathbf{F}$

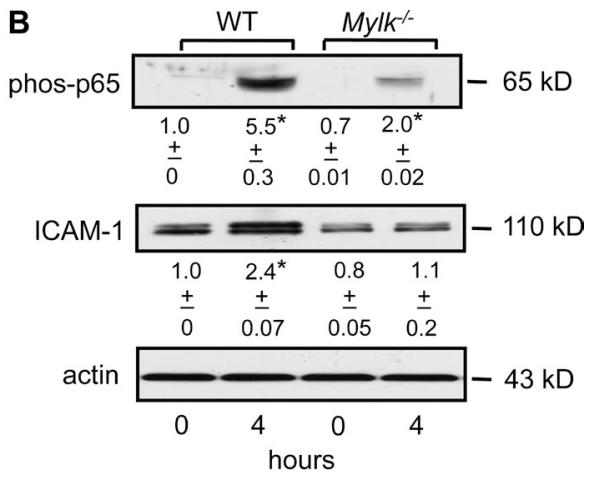

E

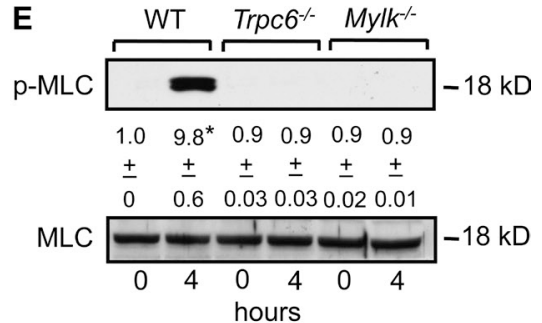

Figure 7. Role of MYLK as a TRPC6 effector mediating increased lung vascular permeability and NF- $\kappa$ B activation. (A) WT and $\mathrm{Mylk}^{-/-}$lungs were perfused with vehicle or $100 \mu \mathrm{M}$ OAG for 20 min, after which $K_{\mathrm{f}, \mathrm{c}}$ was determined. Bar graph shows mean \pm SEM of data from three experiments. * indicates significant increase in $K_{\mathrm{f}, \mathrm{c}}$ values compared with vehicle perfused WT lungs or Mylk-1- lungs perfused with vehicle or OAG $(\mathrm{P}<0.05)$. (B) Lungs from WT and Mylk $\mathrm{k}^{-/-}$ mice were harvested $4 \mathrm{~h}$ after PBS or $1 \mathrm{mg} / \mathrm{ml}$ LPS challenge. Lung lysates were immunoblotted with either phosphoSer536-p65 antibody or ICAM-1 antibody. Blots were probed with anti-actin antibodies to verify equal protein loading. Data represent results from three separate experiments. ${ }^{*}$ indicates values different from values under basal conditions (no LPS; $P<0.05$ ). (C and D) LPS exposed WT and $M y / k^{-1-}$ mice were injected with Evans blue-labeled albumin retroorbitally $30 \mathrm{~min}$ before termination of experiments and lung wet/dry ratio $(\mathrm{C})$ and albumin extravasation from lungs (D) were determined. Data represent mean \pm SEM of three individual experiments. ${ }^{*}$ indicates significant increase from PBS-exposed group $(P<0.05)$. (E) Lungs from WT, Trpc6 ${ }^{-1-}$, and $\mathrm{Mylk}^{-1-}$ mice were harvested $4 \mathrm{~h}$ after PBS or $1 \mathrm{mg} / \mathrm{ml}$ LPS challenge. Lung lysates were immunoblotted with anti-phospho MLC antibody. Blots were stripped and reprobed with anti-MLC antibodies to verify equal protein loading. Data represent results from three separate experiments. * indicates values that are significantly higher between control versus LPS treatment $(P<0.05)$. ( $F$, left $)$ HPAECs were transduced either with dominant-negative TRPC6 (DN-TRPC6) mutant or empty vector for $24 \mathrm{~h}$. Cells were loaded with Fura 2-AM. After 15 min, cells were stimulated with $100 \mu \mathrm{M}$ OAG in $2 \mathrm{mM} \mathrm{Ca}^{2+}$ buffer and changes in intracellular $\mathrm{Ca}^{2+}$ in response to $\mathrm{OAG}$ were determined ratiometrically. Each representative trace is the average response of 20-25 cells, and these experiments were repeated three times. (right) HPAECs transducing DN-TRPC6 mutant or kinase-dead MYLK (KD-MYLK) mutant for $24 \mathrm{~h}$ were stimulated with $1 \mu \mathrm{g} / \mathrm{ml}$ LPS for $4 \mathrm{~h}$. Cell lysates were immunoblotted with phosphoSer536-p65, ICAM-1 or phosphorMLC antibodies. Blots were probed with anti-actin antibodies to verify equal protein loading. Densitometric analysis was performed on data from three separate experiments. ${ }^{*}$ indicates values different from values under basal conditions (no LPS; $\mathrm{P}<0.05$ ). 
possibility that other TRPC channels could have accounted for our findings.

An important question arises as to whether TRPC6dependent lung injury could only be ascribed to lung ECs or whether myeloid cells such as neutrophils were involved. To determine contributions of myeloid cells, TRPC6-null BM cells were transplanted into lethally irradiated WT mice and vice versa. LPS-induced increase in lung vascular permeability and edema formation persisted in WT mice transplanted with $\operatorname{Trpc} 6^{-/-}$BM cells. These experiments also showed that the increased lung vascular permeability and edema formation were prevented in Trpc6 $6^{-/-}$mice, even when mice were transplanted with WT BM cells. Thus, we interpret that TRPC6 expression in ECs (as opposed to myeloid cells) as being responsible for lung vascular permeability and edema induced by LPS.

Because LPS stimulated DAG synthesis and activated TRPC6, we addressed the possibility that DAG activation of TRPC6 could also be responsible for the lung inflammatory component of the LPS response. TRPC6-null mice survived longer after CLP, a severe model of polymicrobial sepsis (Bachmaier et al., 2007; Toya et al., 2011), and the majority of TRPC6-null mice were also resistant to a lethal dose of i.p LPS. In addition, TRPC6-null mice had significantly reduced lung inflammation. Thus, besides the crucial role of TRPC6 in increasing lung vascular permeability, our results demonstrate that TRPC6 signaling is a key regulator of lung inflammation induced by LPS.

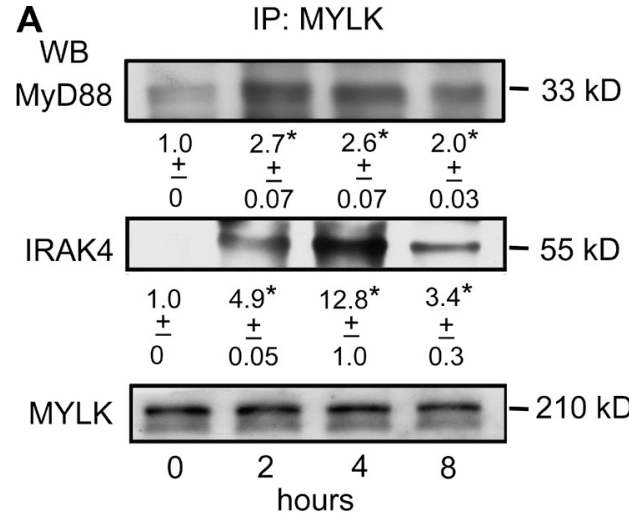

C

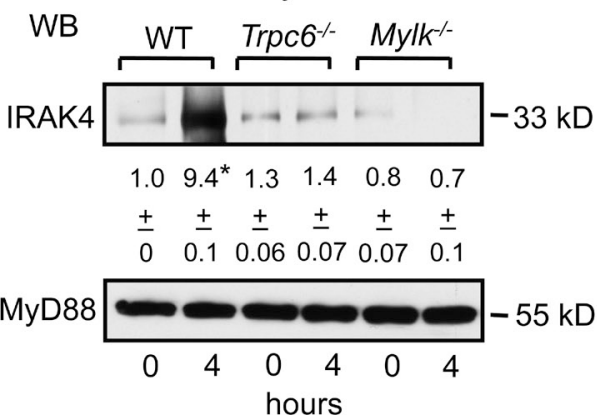

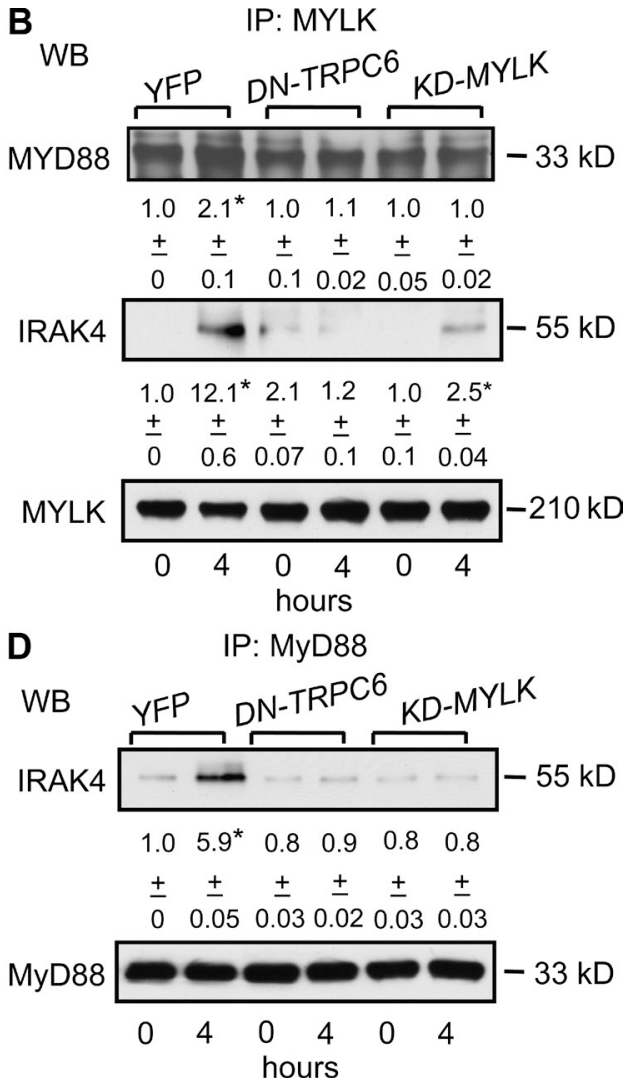

Figure 8. TRPC6-mediated $\mathrm{Ca}^{2+}$ entry and resultant MYLK activation induce MyD88 interaction with IRAK4. (A) WT mice were exposed to nebulized PBS or LPS for $1 \mathrm{~h}$ and their lungs were harvested after 2, 4, and $8 \mathrm{~h}$ after LPS exposure. Lung lysates were immunoprecipitated with anti-MYLK antibody, followed by immunoblotting either with anti-MyD88, anti-IRAK4, or anti-MYLK antibodies. Data represent mean \pm SD of densitometric values from three individual experiments. * indicates significant increase from PBS-exposed group. (B) HPAECs were transduced either with DN-TRPC6 mutant or KD-MYLK mutant and, $24 \mathrm{~h}$ after transfection, cells were stimulated with $1 \mu \mathrm{g} / \mathrm{ml}$ LPS for $4 \mathrm{~h}$. Cell lysates were either immunoprecipitated with anti-MYLK or anti-MyD88 antibody and immunoblotted with either IRAK4 antibody or MyD88 antibody to determine interaction. Data represent mean \pm SD densitometric values from three individual experiments. * indicates significant increase from control transfected cells $(\mathrm{P}<0.05)$. (C) Lungs from WT, Trpc6 ${ }^{-/-}$, and $\mathrm{Mylk}^{-1-}$ mice were harvested $4 \mathrm{~h}$ after PBS or $1 \mu \mathrm{g} / \mathrm{ml}$ LPS challenge. Lung lysates were immunoprecipitated with anti-MyD88 antibody and immunoblotted with either anti-IRAK4 or anti-MyD88 antibodies. Data represent mean \pm SD of three densitometric values from three individual experiments. * indicates significant increase from PBS-exposed group (P < 0.05). (D) HPAECs transducing DN-TRPC6 mutant or KD-MYLK mutant were stimulated with $1 \mu \mathrm{g} / \mathrm{ml}$ LPS for $4 \mathrm{~h}$. Cell lysates were either immunoprecipitated with anti-MYLK or anti-MyD88 antibody and immunoblotted with either IRAK4 antibody or MyD88 antibody to determine interaction. Data represent mean \pm SD densitometric values from three individual experiments. ${ }^{*}$ indicates significant increase from control transfected cells $(P<0.05)$. 
A

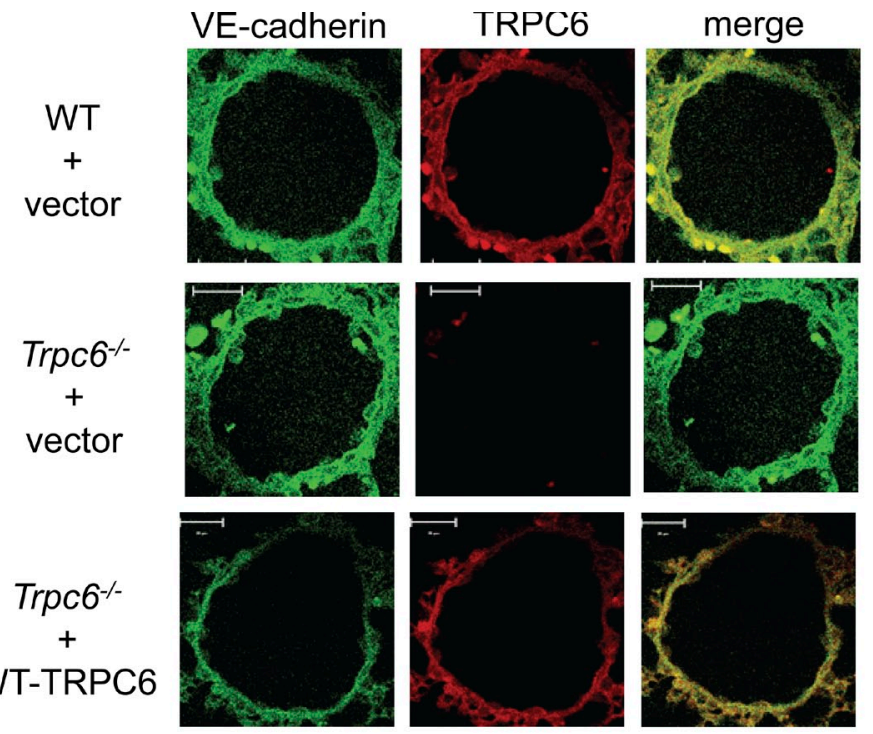

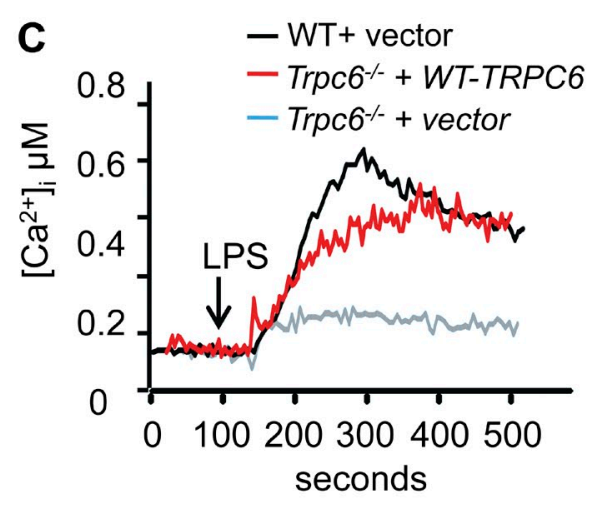

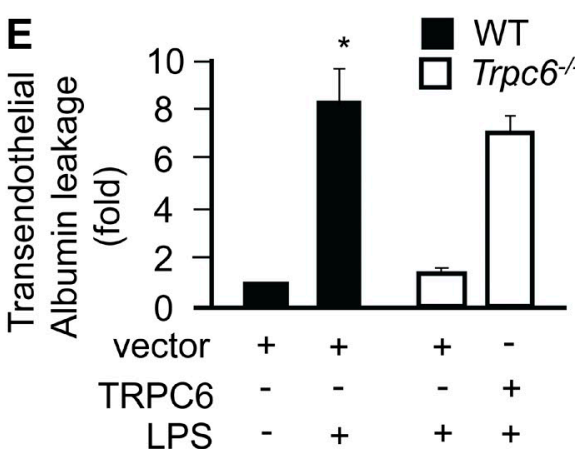

Figure 9. Restoring TRPC expression in Trpc6 ${ }^{-/-}$mice rescues LPS-induced lung vascular permeability phenotype.

WT or Trpc6 $6^{-1-}$ mice were retroorbitally injected with liposome encapsulating either empty vector or WT-TRPC6 cDNA. After $48 \mathrm{~h}$, lungs were harvested, sectioned and co-immunostained with anti-TRPC6 and anti-VE-cadherin antibody to confirm TRPC6 protein expression in endothelium (A). Images represent results from at least two independent experiments. Bars, $10 \mu \mathrm{m}$. In parallel, WT and Trpc6 $6^{-1-}$ MLECs were transfected with vector or WT-TRPC6 cDNA. After $24 \mathrm{~h}$ transfection, changes in intracellular $\mathrm{Ca}^{2+}$ in response to OAG (B) and LPS (C) were determined. (D and E) WT or Trpc6 $^{-1-}$ mice expressing vector or WT-TRPC6 CDNA were exposed to nebulized $1 \mathrm{mg} / \mathrm{ml}$ LPS for $1 \mathrm{~h} .4 \mathrm{~h}$ later, lung wet/dry ratio (D) and lung albumin uptake (E) were determined. Data are represented as mean \pm SEM of three independent experiments. * indicates significance from WT PBS-exposed lungs or lungs not receiving LPS $(P<0.05)$.

A key question is how TRPC6 mediates both TLR4-induced increases in lung vascular permeability and NF- $\mathrm{\kappa B}-$ dependent lung inflammation. Thus, we focused on the role of MYLK, the $\mathrm{Ca}^{2+}$ calmodulindependent nonmuscle isoform of MYLK (Garcia et al., 1997; Mehta and Malik, 2006; Rossi et al., 2007), which is required for actomyosinmediated endothelial contraction and disruption of endothelial junctions that control endothelial barrier function (Garcia et al., 1995, 1997; Mehta and Malik, 2006; Rossi et al., 2007). Based on findings that LPS activation of TRPC6 failed to phosphorylate MLC in MYLK-null ECs, and

To address mechanisms of TRPC6-induced lung inflammation, we focused on the role of TRPC6 in regulating NF- $\kappa B$ activity. In lungs from TRPC6-null mice, LPS failed to induce $\mathrm{p} 65$ phosphorylation, a measure of NF- $\mathrm{\kappa B}$ activity (Nicholas et al., 2007), indicating the involvement of TRPC6 in the mechanism of NF- $\mathrm{KB}$ activation. LPS-induced ICAM-1 expression and IL-6, TNF, and KC production were also abrogated in TRPC6-null mouse lungs. Strikingly, rescuing TRPC6 expression in TRPC6-null mice restored the LPS-induced lung inflammation response demonstrating that TRPC6 is both required and sufficient for mediating the LPSinduced lung vascular permeability. lung vascular permeability therefore remained unaltered in MYLK-null mice, we identified MYLK as a crucial effector of TRPC6 signaling. LPS also failed to induce NF-кB activation and lung inflammation in MYLK-null mice, further supporting the central role of MYLK downstream of TRPC6 in signaling both lung vascular permeability and inflammation responses to LPS.

TLR4 induces the immune response by activating the adaptor MyD88 and recruiting IRAK4, which then phosphorylates IRAK1 and IRAK2 to induce NF- $\mathrm{KB}$ activity (Medvedev et al., 2002; Kawagoe et al., 2008; Takeuchi and Akira, 2010). Besides its role in mediating actomyosin, 
MYLK cross-bridging can function as a scaffold mediating protein that promotes interactions via a specialized 922-aa N-terminal domain (Garcia et al., 1997; Verin et al., 1998; Mehta and Malik, 2006; Wadgaonkar et al., 2005b). Studies have identified cortactin, $\beta 2$ integrin, and macrophage inhibitory factor as MYLK partners (Garcia et al., 1997; Verin et al., 1998; Wadgaonkar et al., 2005a,b; Mehta and Malik, 2006). Because TRPC6 activation of MYLK was required for NF- $\kappa \mathrm{B}$ activation in response to LPS, we considered whether MYLK mediates TLR4 signaling by promoting MyD88 and IRAK4 assembly. We observed in fact that MYLK immunoprecipitated with MyD88 and IRAK4, and that MyD88 interaction with MYLK preceded that of MyD88 with IRAK4. Moreover, LPS failed to induce MyD88 interaction with IRAK4 in lungs lacking either TRPC6 or MYLK. In addition, TRPC6-mediated $\mathrm{Ca}^{2+}$ entry and MYLK activity were required for the crucial interaction between MyD88 and IRAK4. MyD88 failed to bind IRAK4 in response to LPS in ECs expressing either DNTRPC6 mutant or KD-MYLK mutant, and as a consequence NF- $\kappa \mathrm{B}$ remained inactive. These observations best fit a model in which DAG generation after LPS exposure induces TRPC6-mediated $\mathrm{Ca}^{2+}$ entry and activates MYLK, which functions as a scaffold mediating MyD88-IRAK4 interaction and inducing NF- $\mathrm{kB}-$ dependent lung inflammation.

Although our findings help to explain the central role of TRPC6-mediated $\mathrm{Ca}^{2+}$ entry in mediating MyD88-IRAK4 interaction, details of TRPC6-regulated interaction remain unclear. Structural analysis showed that interaction between MyD88 and IRAK2 required their death domains, which is initiated by oligomerization of MyD88 death domain (Loiarro et al., 2009; Lin et al., 2010). Although MYLK does not contain a canonical death domain, the presence of several serine/threonine residues in this MyD88 domain (Loiarro et al., 2009; Lin et al., 2010) suggests that they might serve as substrates for MYLK and could induce MyD88 oligomerization and its interaction with IRAK4. The finding that the kinase-defective MYLK mutant failed to interact with MyD88 and prevent MyD88-IRAK4 interaction supports this concept.

The present studies have identified DAG-activated TRPC6 channel as a key mechanism, signaling both LPSinduced lung vascular permeability and inflammation. LPS results in DAG production, which activates TRPC6, and the activated TRPC6 induces MYLK activity that by stimulating actomyosin cross-bridging mediates $\mathrm{EC}$ contraction and leads to increased lung vascular permeability. Additionally, activated MYLK promotes MyD88 interaction with IRAK4, thereby triggering NF- $\kappa B$ signaling and pulmonary inflammation. Thus, our findings place TRPC6 at the center of the signaling pathways mediating ALI owing to its dual role in increasing lung vascular permeability and mediating TLR4 signaling, which causes lung inflammation through NF- $\mathrm{\kappa B}$ activation. Because of this pivotal role of TRPC6, we suggest that TRPC6 is potentially useful target for preventing ALI induced by endotoxemia.

\section{MATERIALS AND METHODS}

Materials. HPAECs, endothelial growth medium (EBM-2), and nucleofector kit and electroporation system were obtained from Lonza. FuGENE transfection reagent was procured from Promega. Anti-Alexa Fluor-568 and -488 antibodies and ProLong Gold antifade were obtained from Invitrogen. Anti-phospho P65, anti-ICAM1, anti-MYLK, anti-VE-cadherin, and protein $A / G$ agarose beads were purchased from Santa Cruz Biotechnology. Mouse anti-rabbit IgG (conformation specific), anti-phospho MLC, antiMyD88, and anti-IRAK4 antibodies were purchased from Cell Signaling Technology. Immunohistochemistry of lung sections was performed using anti-TRPC6 antibody from Sigma-Aldrich, while FACS analysis was performed using anti-TRPC6 antibody from Millipore or APC-VE-cadherin and PE-PECAM1 antibodies from eBioscience.

Animals. All animal studies were approved by the Institutional Animal Care and Use Committee of University of Illinois. Trpc $6^{-/-}$mice breeding pair in a C57Blk/6J background was initially obtained from National Institute of Environment and Health Sciences (NC); $M y l k^{-/-}$mice breeding pair in a C57Blk/6J background was obtained from M. Watterson (Northwestern University, Chicago, IL). Trpc $6^{-1-}$ and $\mathrm{Mylk}^{-/-}$mice colony was maintained at pathogen-free animal housing facility at the University of Illinois at Chicago (UIC). C57Blk/6J mice initially acquired from The Jackson Laboratory and bred at UIC were used as WT controls. All experiments were performed on 8-10-wk-old mice.

EC culture. MLECs were isolated as previously described (Tiruppathi et al., 2002). In brief, blood-free mouse lungs were minced, digested with collagenase at $37^{\circ} \mathrm{C}$ for $45 \mathrm{~min}$, triturated, and centrifuged at 3,000 rpm. Cell suspension was incubated with PECAM-1-coated Dynabeads for $1 \mathrm{~h}$, after which ECs were magnetically sorted. Isolated ECs were plated on fibronectin-coated T-25 flasks and cultured with DME containing endothelial growth supplement. Cells were trypsinized and characterized by FACS analysis using antiVE-cadherin, anti-VEGFR2, and anti-CD31 antibodies, which are known EC surface markers. We also determined tube formation in Matrigel as additional indices of EC characteristics. Isolated MLECs were $>90 \%$ pure.

HPAECs were cultured in a T-75 flask coated with gelatin and growth factor-supplemented EGM2 medium, as previously described (Knezevic et al., 2007).

Transfection of cells. cDNA was transduced into MLECs using FuGENE transfection reagent according to the manufacturer's protocol. Human pulmonary artery ECs were transfected with cDNA using a Nucleofector device obtained from Lonza (Singh et al., 2007; Kini et al., 2010).

Dominant-negative (DN)-TRPC6 mutant (T. Sharma, University of Illinois, Chicago, IL) was generated by deleting LFW sequence $(\Delta 678-680$ a) from full-length TRPC6 cDNA. LFW motif is a structural part of the pore helix of TRPC6 channel (Hofmann et al., 1999)

Plasmid pEYFP-N1-TRPC6-WT containing the full-length Homo sapiens TRPC6 (available from GenBank under accession no. NM_004621) was used as a DNA template with DNA polymerase Phusion (Finnzymes) in a two-step PCR method to generate C-terminal YFP tag TRPC6 with deletion of LFW (aa 678-680). In the first step, two PCR fragments were generated using the following primer pairs: fragment A primer pairs, GFP-494-F, 5'-ATGTCGTAACAACTCCGCCCCATTGA-3', andTRPC6-dAA67880-R, 5'-CAAAATATAGC/TGTCTTAAAACTCTCTTCAACTG-3'; fragment B primer pairs, TRPC6-dAA678-80-F, 5'-TTTAAGACA/ GCTATATTTGGACTTTCTGAAGTG-3', and YFP-820-R, 5'-TGAACTTCAGGGTCAGCTTGC-3'. As shown in the primers TRPC6-dAA67880-F and TRPC6-dAA678-80-R, the forward slash indicated the three amino acids being deleted (aa 678-680 or LFW residues). In the second step of PCR, a final PCR product, fragment $\mathrm{C}$ was generated by combining fragments $\mathrm{A}$ and $\mathrm{B}$ together as PCR DNA templates with primer pair GFP-494-F and YFP-820-R. Fragment $C$ was digested with restriction enzymes $5^{\prime}-E c o R 1$ and $3^{\prime}-$ AgeI (New England Biolabs, Inc.) and ligated to the pEYFP-N1 vector (BD) also digested at the same restriction enzyme sites. The resulting plasmid was verified and analyzed by gel analysis and sequencing analysis. 
Immunoprecipitation. Lungs or ECs were lysed in modified RIPA buffer, and equal amounts of protein were immunoprecipitated with appropriate antibodies over night at $4^{\circ} \mathrm{C}$, followed by the addition of protein $\mathrm{A} / \mathrm{G}$ agarose beads for $4 \mathrm{~h}$ at $4^{\circ} \mathrm{C}$, as described previously (Knezevic et al., 2009). For determining IRAK4 interaction with MYLK or MyD88, blots were first incubated with anti-IRAK4 antibody overnight, followed by reincubation with conformation specific mouse anti-rabbit antibody (Cell Signaling Technology) to eliminate the background from heavy chain.

RT-PCR. Total RNA was isolated from mice lungs or MLECs using TRIzol agent (Invitrogen) according to the manufacturer's instructions. RNA was quantified spectrophotometrically and reverse-transcribed using specific primers to determine the expression of various TRPC or ICAM-1 (Tiruppathi et al., 2002; Dietrich et al., 2005b; Tauseef et al., 2008).

FRET-based DAG generation and $\mathrm{Ca}^{2+}$ entry assessment. WT or Trpc6 $6^{-1-}$ MLECs were transfected with FRET-based DAG (DAGR; A. Newton, University of California, San Diego, La Jolla, CA) or $\mathrm{Ca}^{2+}$ reporter (Y. Wang, University of Illinois, Champaign, IL), and DAG generation and $\mathrm{Ca}^{2+}$ mobilization were determined by direct FRET analysis in live cells. DAGR mutant was purchased from Addgene (plasmid \#14865). Cells were stimulated with $1 \mu \mathrm{g} / \mathrm{ml}$ LPS and images were captured every $15 \mathrm{~s}$. An image stack was generated with a 458-nm laser line spanning and emission wavelength ranging from $463-602 \mathrm{~nm}$ with $10.7-\mathrm{nm}$ bandwidths. At each time point, three images were recorded: CFP, FRET, and YFP. All images were corrected for shading and background was subtracted. Threshold FRET images were used to generate a binary mask that was then divided by the corresponding CFP images to yield a ratio image reflecting DAG generation and $\mathrm{Ca}^{2+}$ mobilization. Data were analyzed by MetaMorph software.

Cytosolic $\mathrm{Ca}^{2+}$ measurements. An increase in intracellular $\mathrm{Ca}^{2+}$ was measured using the $\mathrm{Ca}^{2+}$-sensitive fluorescent dye Fura 2-AM as previously described (Singh et al., 2007). The intracellular $\mathrm{Ca}^{2+}$ concentration $\left(\left[\mathrm{Ca}^{2+}\right] \mathrm{i}\right)$ was calculated using Invitrogen Fura- $2 \mathrm{Ca}^{2+}$ Imaging Calibration kit according to the manufacturer's protocol and the equation: $\left[\mathrm{Ca}^{2+}\right]_{\text {free }}=K_{\mathrm{d}}^{\mathrm{EGTA}} \times$ $\left[\left(\mathrm{R}-\mathrm{R}_{\min }\right) /\left(\mathrm{R}_{\max } \mathrm{R}\right)\right] \times\left[\mathrm{F}^{380}{ }_{\max } / \mathrm{F}^{380}{ }_{\min }\right] . K_{\mathrm{d}}$ represent the dissociation constant of Fura2- $\mathrm{Ca}^{2+}$ interaction, $\mathrm{R}$ is fluorescence ratio, $\mathrm{R}_{\min }$ is the ratio at zero free calcium, $R_{\max }$ is the ratio at saturation calcium $(39 \mu \mathrm{M}), \mathrm{F}^{380}{ }_{\max }$ is the fluorescence intensity with excitation at $380 \mathrm{~nm}$, for zero free $\mathrm{Ca}^{2+}$; and F380 min is the fluorescence intensity at saturating free $\mathrm{Ca}^{2+}$.

Patch-clamping of ECs. We performed the whole-cell patch-clamp technique to determine cationic currents, as previously described (Hofmann et al., 1999; Obukhov and Nowycky, 2005). The currents were acquired during 300 -ms voltage ramps from -100 to $+100 \mathrm{mV}$, with a 2 -s inter-ramp interval using the Optopatch amplifier controlled by PCLAMP 10 software (Molecular Devices). The current amplitudes at $-90 \mathrm{mV}$ were plotted as a function of time. The pipette solution contained (in mM): $10 \mathrm{EGTA} ; 3.77 \mathrm{CaCl}_{2}$; $2 \mathrm{MgCl}_{2} ; 125 \mathrm{CsMeSO}_{3}$; and 10 Hepes. The standard extracellular solution contained (in mM): $145 \mathrm{NaCl} ; 1.2 \mathrm{CaCl}_{2} ; 1 \mathrm{MgCl}_{2} ; 2.5 \mathrm{KCl} ; 10$ Hepes; and 5.5 Glucose. The $\mathrm{pH}$ of all solutions was adjusted to 7.2. The PCLAMP 10 software package (Molecular Devices) was used for data analysis. All electrophysiological experiments were performed at room temperature $\left(22-23^{\circ} \mathrm{C}\right)$.

LPS challenge. $\operatorname{Trpc} 6^{-1-}, M y l k^{-/-}$and WT mice housed in sealed container were exposed to a nebulized solution of lyophilized E. coli LPS in sterile saline $(1 \mathrm{mg} / \mathrm{ml})$ for $1 \mathrm{~h}$ at a driving flow rate $(8 \mathrm{liter} / \mathrm{min})$ using a small volume nebulizer (Resigard II; Marquest Medical, Englewood, CO) and sacrificed after the indicated times (Tauseef et al., 2008).

Polymicrobial sepsis model. Polymicrobial sepsis was induced by CLP as previously described (Bachmaier et al., 2007; Toya et al., 2011). In brief, animals were anesthetized using $100 \mathrm{mg} / \mathrm{kg}$ ketamine and $15 \mathrm{mg} / \mathrm{kg}$ xylazine. Cecum was exposed via a midline abdominal incision, ligated below the ileocecal valve, and punctured using 18-gauge needle in mesenteric-antimesenteric direction. Peritoneal and skin wounds were closed using 6-0 silk sutures. Immediately after surgery, mice were resuscitated by subcutaneous injection of $1 \mathrm{ml}$ of prewarmed $0.9 \%$ saline solution. Mice were monitored every $6 \mathrm{~h}$ for $7 \mathrm{~d}$ to determine their survival.

Lung vascular liposomal delivery of cDNA for rescue experiments. Cationic liposomes were made using a mixture of dimethyldioctadecylammonium bromide and cholesterol in chloroform, as described previously (Holinstat et al., 2006; Knezevic et al., 2009). Vector or WT-TRPC6-cDNA $(50 \mu \mathrm{g})$ were mixed with $100 \mu \mathrm{l}$ of liposomes. Liposomes encapsulating cDNA were injected into mouse vasculature via retroorbital injection. After $48 \mathrm{~h}$, mouse lungs were used for determining lung vascular permeability or protein expression (Tauseef et al., 2008).

Immunohistochemistry. Formalin-fixed, 4- $\mu$ m-thick lung sections were co-immunostained with anti-TRPC6 and VE-cadherin antibodies along with appropriate Alexa Fluor-labeled secondary antibodies using manufacture protocol (Bethyl Laboratories, Inc.). Lung sections were visualized with a LSM510 confocal microscope (Carl Zeiss, Inc.; Tauseef et al., 2008).

Assessment of lung vascular permeability to albumin. Evans blue-conjugated albumin (EBA; $20 \mathrm{mg} / \mathrm{kg}$ ) was injected retroorbitally $30 \mathrm{~min}$ before sacrificing the mice to determine vascular permeability, as described previously (Peng et al., 2004; Tauseef et al., 2008; Knezevic et al., 2009). In brief, blood was obtained from the right ventricle of the heart into heparinized syringes and plasma was separated. Lungs were homogenized. Lung lysates and plasma were incubated with 2 volumes of formamide for $18 \mathrm{~h}$ at $55-60^{\circ} \mathrm{C}$ and centrifuged at $5,000 \mathrm{~g}$ for $30 \mathrm{~min}$. The optical density of the supernatant was determined spectrophotometrically at $620 \mathrm{~nm}$ (Evans blue) and $740 \mathrm{~nm}$ (hemoglobin correction). EBA extravasation was calculated as EBA influx in lung versus that in plasma.

Measurement of vessel filtration coefficient $\left(\boldsymbol{K}_{f, c}\right)$. Mice were anesthetized with an i.p. injection of ketamine $(100 \mathrm{mg} / \mathrm{kg}$ body weight) and xylazine (15 mg/kg body weight). Lungs were harvested and microvessel permeability was determined in isogravimetric lungs by determining microvascular filtration coefficient $\left(K_{f, c}\right.$; Vogel et al., 2000; Tauseef et al., 2008; Knezevic et al., 2009). In brief, outflow pressure was elevated by $10 \mathrm{~cm} \mathrm{H}_{2} \mathrm{O}$ for $20 \mathrm{~min}$ in isogravimetric perfused lungs. The lung wet weight gain during this time, which is the net fluid accumulation, was recorded. At the end of each experiment, lung dry weight was determined. $\mathrm{K}_{\mathrm{f}, \mathrm{c}}$ (milliliters $\times \min ^{-1} \times$ centimeters $\mathrm{H}_{2} \mathrm{O} \times$ grams dry weight ${ }^{-1}$ ) was calculated from the slope of the recorded weight change normalized to the pressure change and lung dry weight.

Lung edema determination. Left lungs from the same mice used for Evans blue albumin extravasation were excised and completely dried in the oven at $60^{\circ} \mathrm{C}$ overnight for calculation of lung wet/dry ratio (Barnard et al., 1995; Tauseef et al., 2008).

BM transplantation (BMT). WT and $\operatorname{Trpc} 6^{-/-}$mice were exposed to lethal irradiations with $1000 \mathrm{cGy}$ at a dose rate of $100 \mathrm{cGy} / \mathrm{m}$ (Zhao et al., 2006; Weissmann et al., 2012). At $3 \mathrm{~h}$ after irradiation, mice were anesthetized with ketamine $(100 \mathrm{mg} / \mathrm{kg}$, i.p.) and xylazine $(15 \mathrm{mg} / \mathrm{kg}$, i.p. $)$ and injected retroorbitally with $0.2 \mathrm{ml}$ of $3 \times 10^{6}$ donor BM cells (TRPC6-null or WT) using a 27-gauge needle. Experiments were performed 6 wk after confirmation of BM cells transplantation by FACS analysis (see following section; Weissmann et al., 2012; Zhao et al., 2006).

FACS analysis. MLECs were characterized using APC-tagged anti-VE cadherin and PE-tagged anti-CD31 antibodies. Isotype-matched APC- and PE-tagged IgG were used as negative controls. Data were acquired using Cyan-II flow Cytometry (Beckman Coulter, Inc.) and analyzed using Summit software.

For determining the efficiency of BM cells transplantation in mice, BM cells were isolated from chimera mice. Cells were fixed and permeabilized 
with BD Cytofix/Cytoperm solution. These cells were incubated with antiTRPC6 antibody for $30 \mathrm{~min}$, followed by Alexa Fluor 488 secondary antibody. Size scatter analysis was performed using FACS analyzer to confirm the percentage of the TRPC6-expressing population (Kini et al., 2010). The analysis was done using WinMdi software. Dot blots were plotted after gating all BM cells from respective groups of mice against side scatter population.

Statistical analysis. Comparisons between experimental groups were made by one-way ANOVA and post-hoc test. Differences in mean values were considered significant at $\mathrm{P}<0.05$.

We dedicate this paper to our colleague Dr. Monica Smith who passed away during the completion of these studies.

We greatly appreciate Dr. Tiffany Sharma; Dr. Yulia Komarova for her advice to Dr. Monica Smith with FRET and Metamorph analysis software; and Ms. Vidisha Kini for her help during the preparation of this manuscript. We also acknowledge Dr. Alexandra C. Newton; Dr. Yingxiao Wang; Dr. Martin Watterson; and Dr. Patricia Gallagher (Indiana University, Indianapolis, IN, for KD-MYLK mutant).

This work was supported by National Institutes of Health grants HL71794 (D. Mehta), HL84153 (D. Mehta) and P01-HL60678 (D. Mehta and A.B. Malik), American Heart Association postdoctoral fellowship to M. Tauseef (10P0ST2600336), and in part by the Intramural Research Division of the National Institutes of Health (project Z01-ES-101684 to LB).

The authors have no conflicting financial interests.

Submitted: 1 July 2011

Accepted: 27 August 2012

\section{REFERENCES}

Andonegui, G., S.M. Goyert, and P. Kubes. 2002. Lipopolysaccharideinduced leukocyte-endothelial cell interactions: a role for CD14 versus toll-like receptor 4 within microvessels. J. Immunol. 169:2111-2119.

Andonegui, G., C.S. Bonder, F. Green, S.C. Mullaly, L. Zbytnuik, E. Raharjo, and P. Kubes. 2003. Endothelium-derived Toll-like receptor-4 is the key molecule in LPS-induced neutrophil sequestration into lungs. J. Clin. Invest. 111:1011-1020.

Andonegui, G., H. Zhou, D. Bullard, M.M. Kelly, S.C. Mullaly, B. McDonald, E.M. Long, S.M. Robbins, and P. Kubes. 2009. Mice that exclusively express TLR 4 on endothelial cells can efficiently clear a lethal systemic Gram-negative bacterial infection. J. Clin. Invest. 119:1921-1930.

Bachmaier, K., S. Toya, X. Gao, T. Triantafillou, S. Garrean, G.Y. Park, R.S. Frey, S. Vogel, R. Minshall, J.W. Christman, et al. 2007. E3 ubiquitin ligase Cblb regulates the acute inflammatory response underlying lung injury. Nat. Med. 13:920-926. http://dx.doi.org/10.1038/nm1607

Barnard, J.W., M.G. Biro, S.K. Lo, S. Ohno, M.A. Carozza, M. Moyle, H.R. Soule, and A.B. Malik. 1995. Neutrophil inhibitory factor prevents neutrophil-dependent lung injury. J. Immunol. 155:4876-4881.

Bertocchi, C., M. Traunwieser, J. Dörler, J. Hasslacher, M. Joannidis, and S. Dunzendorfer. 2011. Atorvastatin inhibits functional expression of proatherogenic TLR2 in arterial endothelial cells. Cell. Physiol. Biochem. 28:625-630. http://dx.doi.org/10.1159/000335758

Blue, E.K., Z.M. Goeckeler, Y. Jin, L. Hou, S.A. Dixon, B.P. Herring, R.B. Wysolmerski, and P.J. Gallagher. 2002. 220- and 130-kDa MLCKs have distinct tissue distributions and intracellular localization patterns. Am. J. Physiol. Cell Physiol. 282:C451-C460.

Cheng, H.W., A.F. James, R.R. Foster, J.C. Hancox, and D.O. Bates. 2006. VEGF activates receptor-operated cation channels in human microvascular endothelial cells. Arterioscler. Thromb. Vasc. Biol. 26:1768-1776. http://dx.doi.org/10.1161/01.ATV.0000231518.86795.0f

Di, A., T. Kawamura, X.P. Gao, H. Tang, E. Berdyshev, S.M. Vogel, Y.Y. Zhao, T. Sharma, K. Bachmaier, J. Xu, and A.B. Malik. 2010. A novel function of sphingosine kinase 1 suppression of JNK activity in preventing inflammation and injury. J. Biol. Chem. 285:15848-15857. http:// dx.doi.org/10.1074/jbc.M109.075549

Di, A., X.P. Gao, F. Qian, T. Kawamura, J. Han, C. Hecquet, R.D. Ye, S.M. Vogel, and A.B. Malik. 2012. The redox-sensitive cation channel TRPM2 modulates phagocyte ROS production and inflammation. Nat. Immunol. 13:29-34. http://dx.doi.org/10.1038/ni.2171
Diaz, J.V., R. Brower, C.S. Calfee, and M.A. Matthay. 2010. Therapeutic strategies for severe acute lung injury. Crit. Care Med. 38:1644-1650. http://dx.doi.org/10.1097/CCM.0b013e3181e795ee

Dietrich, A., H. Kalwa, B.R. Rost, and T. Gudermann. 2005a. The diacylgylcerol-sensitive TRPC3/6/7 subfamily of cation channels: functional characterization and physiological relevance. Pflugers Arch. 451:72-80. http://dx.doi.org/10.1007/s00424-005-1460-0

Dietrich, A., M. Mederos Y Schnitzler, M. Gollasch, V. Gross, U. Storch, G. Dubrovska, M. Obst, E. Yildirim, B. Salanova, H. Kalwa, et al. 2005b. Increased vascular smooth muscle contractility in TRPC6-/- mice. Mol. Cell. Biol. 25:6980-6989. http://dx.doi.org/10.1128/MCB.25.16.69806989.2005

Edfeldt, K., J. Swedenborg, G.K. Hansson, and Z.Q. Yan. 2002. Expression of toll-like receptors in human atherosclerotic lesions: a possible pathway for plaque activation. Circulation. 105:1158-1161.

Everhart, M.B., W. Han, T.P. Sherrill, M. Arutiunov, V.V. Polosukhin, J.R. Burke, R.T. Sadikot, J.W. Christman, F.E. Yull, and T.S. Blackwell. 2006. Duration and intensity of NF-kappaB activity determine the severity of endotoxin-induced acute lung injury. J. Immunol. 176:4995-5005.

Gao, X.P., T.J. Standiford, A. Rahman, M. Newstead, S.M. Holland, M.C. Dinauer, Q.H. Liu, and A.B. Malik. 2002. Role of NADPH oxidase in the mechanism of lung neutrophil sequestration and microvessel injury induced by Gram-negative sepsis: studies in p47phox-/- and gp91phox-/mice. J. Immunol. 168:3974-3982.

Garcia, J.G., H.W. Davis, and C.E. Patterson. 1995. Regulation of endothelial cell gap formation and barrier dysfunction: role of myosin light chain phosphorylation. J. Cell. Physiol. 163:510-522. http://dx.doi.org/ 10.1002/jcp.1041630311

Garcia, J.G., V. Lazar, L.I. Gilbert-McClain, P.J. Gallagher, and A.D. Verin. 1997. Myosin light chain kinase in endothelium: molecular cloning and regulation. Am. J. Respir. Cell Mol. Biol. 16:489-494.

Garrean, S., X.P. Gao, V. Brovkovych, J. Shimizu, Y.Y. Zhao, S.M. Vogel, and A.B. Malik. 2006. Caveolin-1 regulates NF-kappaB activation and lung inflammatory response to sepsis induced by lipopolysaccharide. J. Immunol. 177:4853-4860.

Giannone, G., B.J. Dubin-Thaler, H.G. Döbereiner, N. Kieffer, A.R. Bresnick, and M.P. Sheetz. 2004. Periodic lamellipodial contractions correlate with rearward actin waves. Cell. 116:431-443. http://dx.doi .org/10.1016/S0092-8674(04)00058-3

Hofmann, T., A.G. Obukhov, M. Schaefer, C. Harteneck, T. Gudermann, and G. Schultz. 1999. Direct activation of human TRPC6 and TRPC3 channels by diacylglycerol. Nature. 397:259-263. http://dx.doi.org/ $10.1038 / 16711$

Holinstat, M., N. Knezevic, M. Broman, A.M. Samarel, A.B. Malik, and D. Mehta. 2006. Suppression of RhoA activity by focal adhesion kinase-induced activation of p190RhoGAP: role in regulation of endothelial permeability. J. Biol. Chem. 281:2296-2305. http://dx.doi.org/ 10.1074/jbc.M511248200

Into, T., Y. Kanno, J. Dohkan, M. Nakashima, M. Inomata, K. Shibata, C.J. Lowenstein, and K. Matsushita. 2007. Pathogen recognition by Toll-like receptor 2 activates Weibel-Palade body exocytosis in human aortic endothelial cells. J. Biol. Chem. 282:8134-8141. http://dx.doi .org/10.1074/jbc.M609962200

Karpurapu, M., X. Wang, J. Deng, H. Park, L. Xiao, R.T. Sadikot, R.S. Frey, U.A. Maus, G.Y. Park, E.W. Scott, and J.W. Christman. 2011. Functional PU.1 in macrophages has a pivotal role in NF-kB activation and neutrophilic lung inflammation during endotoxemia. Blood. 118:5255-5266. http://dx.doi.org/10.1182/blood-2011-03-341123

Kawagoe, T., S. Sato, K. Matsushita, H. Kato, K. Matsui, Y. Kumagai, T. Saitoh, T. Kawai, O. Takeuchi, and S. Akira. 2008. Sequential control of Toll-like receptor-dependent responses by IRAK1 and IRAK2. Nat. Immunol. 9:684-691. http://dx.doi.org/10.1038/ni.1606

Kawai, T., and S. Akira. 2010. The role of pattern-recognition receptors in innate immunity: update on Toll-like receptors. Nat. Immunol. 11:373384. http://dx.doi.org/10.1038/ni.1863

Kawai, T., O. Adachi, T. Ogawa, K. Takeda, and S. Akira. 1999. Unresponsiveness of MyD88-deficient mice to endotoxin. Immunity. 11:115-122. http:// dx.doi.org/10.1016/S1074-7613(00)80086-2 
Kim, T.J., J. Seong, M. Ouyang, J. Sun, S. Lu, J.P. Hong, N. Wang, and Y. Wang. 2009. Substrate rigidity regulates Ca2+ oscillation via RhoA pathway in stem cells. J. Cell. Physiol. 218:285-293. http://dx.doi.org/ $10.1002 /$ jcp. 21598

Kini, V., A. Chavez, and D. Mehta. 2010. A new role for PTEN in regulating transient receptor potential canonical channel 6-mediated Ca2+ entry, endothelial permeability, and angiogenesis. J. Biol. Chem. 285:33082-33091. http://dx.doi.org/10.1074/jbc.M110.142034

Knezevic, N., A. Roy, B. Timblin, M. Konstantoulaki, T. Sharma, A.B. Malik, and D. Mehta. 2007. GDI-1 phosphorylation switch at serine 96 induces RhoA activation and increased endothelial permeability. Mol. Cell. Biol. 27:6323-6333. http://dx.doi.org/10.1128/MCB.00523-07

Knezevic, N., M. Tauseef, T. Thennes, and D. Mehta. 2009. The G protein betagamma subunit mediates reannealing of adherens junctions to reverse endothelial permeability increase by thrombin. J. Exp. Med. 206:2761-2777. http://dx.doi.org/10.1084/jem.20090652

Lin, S.C., Y.C. Lo, and H. Wu. 2010. Helical assembly in the MyD88IRAK4-IRAK2 complex in TLR/IL-1R signalling. Nature. 465:885890. http://dx.doi.org/10.1038/nature09121

Lloyd-Jones, K.L., M.M. Kelly, and P. Kubes. 2008. Varying importance of soluble and membrane CD14 in endothelial detection of lipopolysaccharide. J. Immunol. 181:1446-1453.

Loiarro, M., G. Gallo, N. Fantò, R. De Santis, P. Carminati, V. Ruggiero, and C. Sette. 2009. Identification of critical residues of the MyD88 death domain involved in the recruitment of downstream kinases. J. Biol. Chem. 284:28093-28103. http://dx.doi.org/10.1074/jbc.M109 .004465

Medvedev, A.E., A. Lentschat, L.M. Wahl, D.T. Golenbock, and S.N Vogel. 2002. Dysregulation of LPS-induced Toll-like receptor 4-MyD88 complex formation and IL-1 receptor-associated kinase 1 activation in endotoxin-tolerant cells. J. Immunol. 169:5209-5216.

Mehta, D., and A.B. Malik. 2006. Signaling mechanisms regulating endothelial permeability. Physiol. Rev. 86:279-367. http://dx.doi.org/ 10.1152/physrev.00012.2005

Mehta, D., G.U. Ahmmed, B.C. Paria, M. Holinstat, T. VoynoYasenetskaya, C. Tiruppathi, R.D. Minshall, and A.B. Malik. 2003 RhoA interaction with inositol 1,4,5-trisphosphate receptor and transient receptor potential channel-1 regulates $\mathrm{Ca} 2+$ entry. Role in signaling increased endothelial permeability. J. Biol. Chem. 278:33492-33500. http://dx.doi.org/10.1074/jbc.M302401200

Monick, M.M., A.B. Carter, G. Gudmundsson, R. Mallampalli, L.S. Powers, and G.W. Hunninghake. 1999. A phosphatidylcholine-specific phospholipase $\mathrm{C}$ regulates activation of $\mathrm{p} 42 / 44$ mitogen-activated protein kinases in lipopolysaccharide-stimulated human alveolar macrophages. J. Immunol. 162:3005-3012.

Nicholas, C., S. Batra, M.A. Vargo, O.H. Voss, M.A. Gavrilin, M.D. Wewers, D.C. Guttridge, E. Grotewold, and A.I. Doseff. 2007. Apigenin blocks lipopolysaccharide-induced lethality in vivo and proinflammatory cytokines expression by inactivating NF-kappaB through the suppression of 655 phosphorylation. J. Immunol. 179:7121-7127.

Obukhov, A.G., and M.C. Nowycky. 2005. A cytosolic residue mediates $\mathrm{Mg} 2+$ block and regulates inward current amplitude of a transient receptor potential channel. J. Neurosci. 25:1234-1239. http://dx.doi.org/ 10.1523/JNEUROSCI.4451-04.2005

Peng, X., P.M. Hassoun, S. Sammani, B.J. McVerry, M.J. Burne, H. Rabb, D. Pearse, R.M. Tuder, and J.G. Garcia. 2004. Protective effects of sphingosine 1-phosphate in murine endotoxin-induced inflammatory lung injury. Am.J. Respir. Crit. Care Med. 169:1245-1251. http://dx.doi .org/10.1164/rccm.200309-1258OC

Pocock, T.M., R.R. Foster, and D.O. Bates. 2004. Evidence of a role for TRPC channels in VEGF-mediated increased vascular permeability in vivo. Am. J. Physiol. Heart Circ. Physiol. 286:H1015-H1026. http:// dx.doi.org/10.1152/ajpheart.00826.2003

Ralay Ranaivo, H., N. Carusio, R. Wangensteen, P. Ohlmann, C. Loichot, A. Tesse, K. Chalupsky, I. Lobysheva, J. Haiech, D.M. Watterson, and R. Andriantsitohaina. 2007. Protection against endotoxic shock as a consequence of reduced nitrosative stress in MLCK210-null mice. Am. J. Pathol. 170:439-446. http://dx.doi.org/10.2353/ajpath.2007 .060219
Rossi, J.L., A.V. Velentza, D.M. Steinhorn, D.M. Watterson, and M.S Wainwright. 2007. MLCK210 gene knockout or kinase inhibition preserves lung function following endotoxin-induced lung injury in mice. Am. J. Physiol. Lung Cell. Mol. Physiol. 292:L1327-L1334. http://dx.doi .org/10.1152/ajplung.00380.2006

Sands, W.A., J.S. Clark, and F.Y. Liew. 1994. The role of a phosphatidylcholine-specific phospholipase $\mathrm{C}$ in the production of diacylglycerol for nitric oxide synthesis in macrophages activated by IFN-gamma and LPS. Biochem. Biophys. Res. Commun. 199:461-466. http://dx.doi.org/ 10.1006/bbrc.1994.1251

Sel, S., B.R. Rost, A.O. Yildirim, B. Sel, H. Kalwa, H. Fehrenbach, H. Renz, T. Gudermann, and A. Dietrich. 2008. Loss of classical transient receptor potential 6 channel reduces allergic airway response. Clin. Exp. Allergy.38:1548-1558.http://dx.doi.org/10.1111/j.1365-2222.2008 .03043.x

Singh, I., N. Knezevic, G.U. Ahmmed,V. Kini, A.B. Malik, and D. Mehta. 2007. Galphaq-TRPC6-mediated Ca2+ entry induces RhoA activation and resultant endothelial cell shape change in response to thrombin. J. Biol. Chem. 282:7833-7843. http://dx.doi.org/10.1074/jbc.M608288200

Takeuchi, O., and S. Akira. 2010. Pattern recognition receptors and inflammation. Cell. 140:805-820. http://dx.doi.org/10.1016/j.cell.2010.01.022

Tauseef, M., V. Kini, N. Knezevic, M. Brannan, R. Ramchandaran, H. Fyrst, J. Saba, S.M. Vogel, A.B. Malik, and D. Mehta. 2008. Activation of sphingosine kinase-1 reverses the increase in lung vascular permeability through sphingosine-1-phosphate receptor signaling in endothelial cells. Circ. Res. 103:1164-1172. http://dx.doi.org/10.1161/01 RES.0000338501.84810.51

Tiruppathi, C., M. Freichel, S.M. Vogel, B.C. Paria, D. Mehta, V. Flockerzi, and A.B. Malik. 2002. Impairment of store-operated Ca2+ entry in TRPC4(-/-) mice interferes with increase in lung microvascular permeability. Circ. Res. 91:70-76. http://dx.doi.org/10.1161/01.RES.0000023391 40106.A8

Toya, S.P., F. Li, M.G. Bonini, I. Gomez, M. Mao, K.W. Bachmaier, and A.B. Malik. 2011. Interaction of a specific population of human embryonic stem cell-derived progenitor cells with CD11b+ cells ameliorates sepsis-induced lung inflammatory injury. Am. J. Pathol. 178:313-324. http://dx.doi.org/10.1016/j.ajpath.2010.09.041

Verin, A.D., V. Lazar, R.J. Torry, C.A. Labarrere, C.E. Patterson, and J.G. Garcia. 1998. Expression of a novel high molecular-weight myosin light chain kinase in endothelium. Am. J. Respir. Cell Mol. Biol. 19:758-766.

Violin, J.D., J. Zhang, R.Y. Tsien, and A.C. Newton. 2003. A genetically encoded fluorescent reporter reveals oscillatory phosphorylation by protein kinase C. J. Cell Biol. 161:899-909. http://dx.doi.org/ $10.1083 /$ jcb. 200302125

Vogel, S.M., X. Gao, D. Mehta, R.D. Ye, T.A. John, P. Andrade-Gordon, C. Tiruppathi, and A.B. Malik. 2000. Abrogation of thrombin-induced increase in pulmonary microvascular permeability in PAR-1 knockout mice. Physiol. Genomics. 4:137-145.

Wadgaonkar, R., S.M. Dudek, A.L. Zaiman, L. Linz-McGillem, A.D. Verin, S. Nurmukhambetova, L.H. Romer, and J.G. Garcia. 2005a. Intracellular interaction of myosin light chain kinase with macrophage migration inhibition factor (MIF) in endothelium. J. Cell. Biochem. 95:849-858. http://dx.doi.org/10.1002/jcb.20472

Wadgaonkar, R., L. Linz-McGillem, A.L. Zaiman, and J.G. Garcia. 2005b. Endothelial cell myosin light chain kinase (MLCK) regulates TNFalphainduced NFkappaB activity. J. Cell. Biochem. 94:351-364. http://dx.doi .org/10.1002/jcb. 20250

Wainwright, M.S., J. Rossi, J. Schavocky, S. Crawford, D. Steinhorn, A.V. Velentza, M. Zasadzki, V. Shirinsky, Y. Jia, J. Haiech, et al. 2003. Protein kinase involved in lung injury susceptibility: evidence from enzyme isoform genetic knockout and in vivo inhibitor treatment. Proc. Natl.Acad. Sci. USA. 100:6233-6238. http://dx.doi.org/10.1073/pnas.1031595100

Wang, Y.L., A.B. Malik, Y. Sun, S. Hu, A.B. Reynolds, R.D. Minshall, and G. Hu. 2011. Innate immune function of the adherens junction protein $\mathrm{p} 120$-catenin in endothelial response to endotoxin. J. Immunol. 186:3180-3187. http://dx.doi.org/10.4049/jimmunol.1001252

Weissmann, N., A. Sydykov, H. Kalwa, U. Storch, B. Fuchs, M. Mederos y Schnitzler, R.P. Brandes, F. Grimminger, M. Meissner, M. Freichel, 
et al. 2012. Activation of TRPC6 channels is essential for lung ischaemiareperfusion induced oedema in mice. Nat. Commun. 3:649. http://dx.doi .org/10.1038/ncomms 1660

Xu, S.J., W.J. Gao, B. Cong, C.L. Ma, S.J. Li, Y.L. Ling, Z.Y. Gu, and Y.X Yao. 2005. Effect of cholecystokinin octapeptide on diacylglycerol-PKC signaling pathway in rat pulmonary interstitial macrophages stimulated by lipopolysaccharide. Acta Pharmacol. Sin. 26:1497-1504. http://dx.do .org/10.1111/j.1745-7254.2005.00217.x

Xu, J., X.P. Gao, R. Ramchandran, Y.Y. Zhao, S.M. Vogel, and A.B. Malik. 2008. Nonmuscle myosin light-chain kinase mediates neutrophil transmigration in sepsis-induced lung inflammation by activating beta2 integrins. Nat. Immunol. 9:880-886. http://dx.doi.org/ $10.1038 /$ ni. 1628

Yamamoto, H., K. Hanada, and M. Nishijima. 1997. Involvement of diacylglycerol production in activation of nuclear factor kappaB by a CD14-mediated lipopolysaccharide stimulus. Biochem. J. 325 223-228.
Zhang, F., G. Zhao, and Z. Dong. 2001. Phosphatidylcholine-specific phospholipase C regulates activation of RAW264.7 macrophage-like cells by lipopeptide JBT3002. J. Lenkoc. Biol. 69:1060-1066.

Zhang, L., H.Y. Li, H. Li, J. Zhao, L. Su, Y. Zhang, S.L. Zhang, and J.Y. Miao. 2011. Lipopolysaccharide activated phosphatidylcholinespecific phospholipase C and induced IL-8 and MCP-1 production in vascular endothelial cells. J. Cell. Physiol. 226:1694-1701. http://dx.doi .org/10.1002/jcp.22500

Zhao, Y.Y., X.P. Gao, Y.D. Zhao, M.K. Mirza, R.S. Frey, V.V. Kalinichenko, I.C. Wang, R.H. Costa, and A.B. Malik. 2006. Endothelial cellrestricted disruption of FoxM1 impairs endothelial repair following LPSinduced vascular injury. J. Clin. Invest. 116:2333-2343. http://dx.doi .org/10.1172/JCI27154

Zhou, H., G. Andonegui, C.H. Wong, and P. Kubes. 2009. Role of endothelial TLR4 for neutrophil recruitment into central nervous system microvessels in systemic inflammation. J. Immunol. 183:5244-5250. http://dx.doi.org/10.4049/jimmunol.0901309 